Research Article

\title{
Characteristics of Unloading Creep of Tuffaceous Sandstone in East Tianshan Tunnel under Freeze-Thaw Cycles
}

\author{
Zhijun Zhou $\mathbb{1}^{1},{ }^{1}$ Haochen Zhan $\left({ }^{\circ},{ }^{1}\right.$ Jiangyang $\mathrm{Hu}^{2},{ }^{2}$ and Chenning Ren ${ }^{1}$ \\ ${ }^{1}$ School of Highway, Chang'an University, Xi'an, Shaanxi 710064, China \\ ${ }^{2}$ CCCC First Highway Consultants Co., Ltd., Xi'an, Shaanxi 710000, China
}

Correspondence should be addressed to Haochen Zhan; 2017221037@chd.edu.cn

Received 29 October 2018; Revised 12 February 2019; Accepted 5 March 2019; Published 6 May 2019

Academic Editor: Georgios I. Giannopoulos

Copyright (c) 2019 Zhijun Zhou et al. This is an open access article distributed under the Creative Commons Attribution License, which permits unrestricted use, distribution, and reproduction in any medium, provided the original work is properly cited.

The physicomechanical properties of tunnel surrounding rock are influenced by many factors such as the external environment and freeze-thaw cycles, especially in engineering in high cold regions. To understand the characteristics of freeze-thaw cycles on the creep properties of rocks in high cold regions, a freeze-thaw test, SEM test, triaxial compression test, and triaxial unloading creep test were carried out for tuffaceous sandstone in the G575 East Tianshan Tunnel in Hami, Xinjiang. The results show the following: (1) the freeze-thaw cycle reduces the degree of cementation of mineral particles in a microcosm, manifested on a macro scale by the scaling mode and crack propagation mode; (2) the effect of freeze-thaw cycles reduces the compressive strength and shear strength of rock samples (i.e., ductility enhancement); (3) for tuffaceous sandstone, the unloading process and freeze-thaw cycle each lead to improved creep deformation in rock samples, and radial deformation is more sensitive to rock deformation and failure; and (4) the creep rate of surrounding rock can be reduced by confining pressure. The peak creep rate increased with freezethaw time, as did the overall creep rate. Attention should be paid to deformation within a short period, and necessary supporting and protection measures should be taken to reduce creep.

\section{Introduction}

With the active development of China's economy and ongoing implementation of Western Development Policy, the number of tunnels and other traffic projects under conditions of high altitude, cold, and glacial accumulation deposits continue to increase [1-3]. As a result, new problems have arisen in highway tunnel engineering $[4,5]$. Among them, tunnel engineering in cold area presents several problems not found in non-frozen-soil areas, comprising an important research topic. Permafrost and seasonal permafrost cover about $50 \%$ of the Earth's land area, mainly in Russia, Canada, China, the United States, Alaska, and Northern Europe. China has a wide cold area (Figure 1(a)), with permafrost and seasonal frozen-soil area accounting for more than $70 \%$ of the total region [6-8]. Rock and soil mass are affected by freeze-thaw cycles year-round in the seasonal frozen-soil area, and superstructure stability and safety are directly influenced by temperature changes during the freeze-thaw process [9-11].
Highway tunnels in cold regions have shown that the phenomenon of frost damage is severe [12]. Among 302 large highway tunnels in Hokkaido, 104 were seriously frozen. To eliminate side wall ice and arch icicles, many tunnels have been equipped with electric heating devices that carry substantial costs $[13,14]$. In the Qidaoliang Tunnel in Gansu Province, freeze-thaw cycles compromise the mechanical properties of surrounding rock and lining concrete. Frost heaving of confining pressure leads to concrete cracking, which seriously affects the safety of passing vehicles and pedestrians in tunnels. The occurrence of such freezing damage is closely related to the freeze-thaw cycles of tunnel surrounding rock.

The primary concern in cold-region engineering is freeze-thaw cycles in soil; therefore, many studies have examined permafrost properties. Lee et al. and Johnson et al. summarized the effects of freeze-thaw cycles on resilience modulus $[15,16]$. Lai et al. investigated the effects of freezethaw cycles on soil strength and deformation and established corresponding models [17]. Xie et al. assessed the physical 


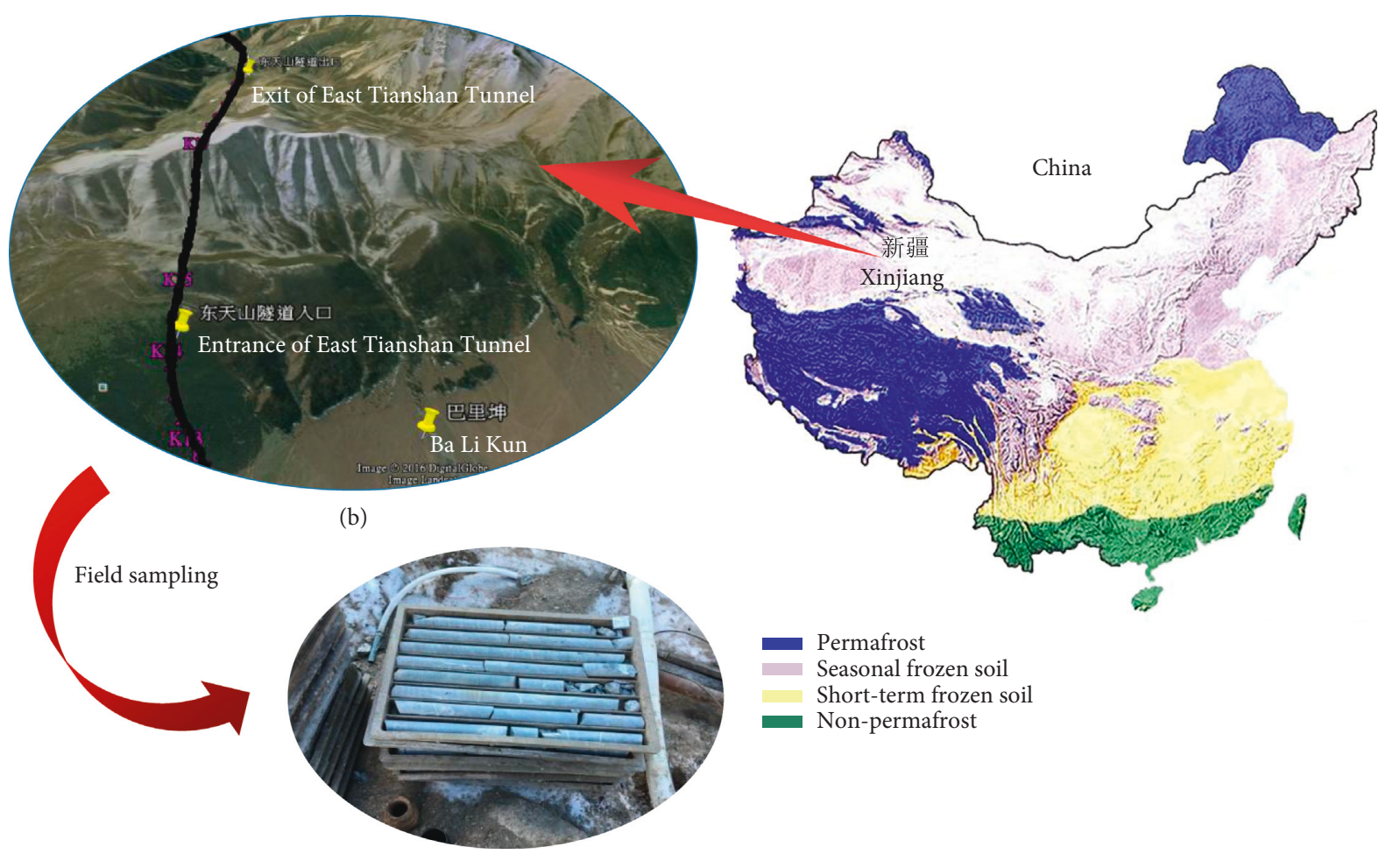

(c)

(a)

Figure 1: (a) Map of permafrost distribution in China. (b) Location of the study area. (c) Some rock samples.

and mechanical properties of Qinghai-Tibet clay under freeze-thaw cycles; results show that freeze-thaw cycles can influence elastic modulus and soil strength substantially [18]. Yang et al. found that under high-stress conditions for seasonal frozen and permafrost soils, the ultimate compressive strength of naturally frozen specimens was lower than that identified in previous studies for remolded frozen silty soils [19]. Numerous studies have been conducted on different types of soil in freeze-thaw cycles with corresponding mechanical models [20-22], summarizing shifts in the physical and mechanical properties of different soils to provide guidance for frozen-soil engineering in various regions [23-25].

For rock-soil mass in cold regions, the effect of pore water is a primary factor influencing the physicomechanical properties of soil, whereas the rock mass is water fracture [26]. The physical and mechanical properties of tunnel surrounding rock comprise an important factor affecting the stability of surrounding rock $[27,28]$. The freeze-thaw cycle exerts a greater impact on the physical and mechanical properties of rock compared with freezing action in frozensoil areas. Therefore, the mechanical properties of tunnel surrounding rock in cold regions are highly complicated. With the development of engineering construction, many countries have conducted research on cold-region environments, which has laid a foundation for the construction and operation of cold-region projects.

Prick and Fahey studied strength variations in shale under freeze-thaw cycles and dry-wet cycles [29, 30]. Matsuoka carried out tests on the relationship between rock strength and freeze-thaw times and determined the freezethaw failure mechanism of rocks [31]. Ruiz et al. used CT technology to scan dolomite under freeze-thaw cycles and found that rock samples did not sustain damage until the freeze-thaw exceeded a certain period [32]. Nicholson and Nicholson applied a freeze-thaw test to study the deterioration of rock samples containing primary fissures [33]. Yambae and Neaupane carried out mechanical experiments by changing the variables of freeze-thaw time, freeze-thaw temperature, confining pressure, and environmental temperature [34]. Yavuz studied the P-wave velocity, porosity, and mechanical parameters of andesite under the combined action of freeze-thaw and thermal shock cycles [35]. Bayram examined the strength loss of rock under freeze-thaw cycles through laboratory tests and established an equation to predict the uniaxial compressive strength of limestone after freeze-thaw cycles [36]. Zhang et al. performed triaxial creep tests on rock salt and obtained creep curves of salt caverns at a steady creep stage [37]. Yang et al. investigated the creep mechanical behavior of red sandstone, presenting an exponential function to characterize the relationship between creep parameters, axial differential stress, and pore pressure [38].

Most studies on the creep characteristics of rock and soil have been based on experimental research under conventional loading conditions [39-41], whereas studies of creep under freeze-thaw cycle rock unloading conditions are relatively limited [42-44]. In this paper, scanning electron microscopy (SEM), triaxial compression, and triaxial unloading creep tests were carried out on tuffaceous 
sandstone under different freeze-thaw cycles to analyze physicomechanical properties, explore the mapping relationship between freeze-thaw cycle times and related mechanical parameters, and consider the creep properties of tuffaceous sandstone under freeze-thaw cycles. Findings complement related research on rock creep and have practical significance for cold-region engineering.

\section{Methodology}

2.1. Materials. The East Tianshan Tunnel is in a cold and high-altitude area in an intensive freeze-thaw region. Rocks in this region have been under freeze-thaw cycles for quite some time. The tunnel entrance is on the north side of the Tianshan Mountains, and the exit is in the Hami area of China (Figure 1(b)). Because of freeze-thaw cycles, the weathering degree of some exposed rocks is severe. Under the long-term influence of natural effects such as rain, wind, and gravity, the tunnel has developed various features such as stone sea, rock burst, underground ice, and freeze-thaw caves. Therefore, tunnel surrounding rock will likely be affected by freeze-thaw cycles during construction and operation, thus changing the physicomechanical properties of the surrounding rock and compromising its stability.

This paper selects tuffaceous sandstone for freeze-thaw cycles and mechanical tests. To eliminate the influence of rock sample dispersion on tests, the following measures were taken: (1) rock samples from the same stratum were selected for comparative tests; (2) samples that were defective and clearly different were eliminated; and (3) the P-wave velocity of rock samples was measured, and those with similar velocity (i.e., within the range of $4200-4600 \mathrm{~m} / \mathrm{s}$ ) were selected for the test. The screening process of rock samples is presented in Figure 2.

To study the physical and mechanical properties of tuffaceous sandstone under freeze-thaw cycles, a standard cylindrical specimen with a diameter of $50 \mathrm{~mm}$ and a height of $100 \mathrm{~mm}$ was selected. Specimens were drilled from the same rock in the field (Figure 1(c)); the axial direction of specimens was perpendicular to the sedimentary direction of rock, and the preparation process aligned with the basic requirements of rock test specification. To ensure comparability of test data and simulate immersion conditions at the construction site, prepared rock samples were screened, and saturation tests were carried out on processed samples before testing. In the saturation test, each sample was immersed vertically in water until the water surface was $3-5 \mathrm{~cm}$ above the top of the sample. Figure 2(e) shows that the mass of each rock sample grew substantially when the immersion time was less than $15 \mathrm{~h}$ and remained nearly unchanged when the immersion time exceeded $36 \mathrm{~h}$. Therefore, the sample was completely saturated after immersion for $72 \mathrm{~h}$.

\subsection{Test Methods}

2.2.1. Freeze-Thaw Cycle Test. The freeze-thaw cycle test used a programmable test chamber between $-30^{\circ} \mathrm{C}$ and $50^{\circ} \mathrm{C}$. The test chamber included a balanced temperature control system that met the requirements of freeze-thaw cycle tests.
According to the temperature in the eastern Tianshan Mountains, the temperature of freeze-thaw cycles was set at $\pm 20^{\circ} \mathrm{C}$, the time interval of temperature conversion was $12 \mathrm{~h}$, and the duration was $24 \mathrm{~h}$. According to test requirements, freeze-thaw cycles were designed for $0,10,20,40$, and 60 days, respectively. The experimental process is shown in Figure 3.

2.2.2. Physical Property Test. To study the physical and mechanical properties of tuffaceous sandstone under freezethaw cycles, a cube sample measuring approximately $10 \mathrm{~mm} \times 10 \mathrm{~mm} \times 10 \mathrm{~mm}$ was selected for the electron microscopy scanning test, and the standard cylinder sample was selected for other tests. Rock samples for wave velocity and quality measurement were numbered $A_{1}, A_{2}, A_{3}, A_{4}$, and $\mathrm{A}_{5}$, respectively. $V_{\mathrm{P}}$ and $M$ denote their average wave velocity and quality increment.

\subsubsection{Triaxial Compression and Unloading Creep Test} Scheme. Tunnel engineering safety is related to many factors $[45,46]$. In an actual engineering environment, rock is typically under three-dimensional stress. First, triaxial compression tests of tuffaceous sandstone using an RMT150 rock mechanics tester (Figure 4(a)) were carried out to obtain the strength and deformation parameters of rock samples under different freeze-thaw cycles. Therefore, the stress level of the rock creep grading unloading test could be reasonably determined. Before testing, rigid cushion blocks were placed on both ends of the rock samples to avoid friction. The confining pressure was set to $20 \mathrm{MPa}$ under loading at $0.1 \mathrm{MPa} / \mathrm{s}$, so the confining pressure and axial pressure reached $20 \mathrm{MPa}$ simultaneously. The confining pressure was then kept constant, and loading continued in the same way until the rock sample was destroyed.

Next, we carried out a triaxial unloading creep test using an RLM-2000 rock triaxial rheometer (Figure 4(b)). This instrument is an automatic rheological servo with a maximum load of $2000 \mathrm{kN}$, maximum confining pressure of $70 \mathrm{MPa}$, maximum axial deformation of $10 \mathrm{~mm}$, and maximum radial deformation of $5 \mathrm{~mm}$. The creep test was divided into separate unloading and grading unloading according to the unloading mode $[47,48]$. Because of its practicability, simple on-site operation, and high-cost performance, the creep test was carried out via staged unloading in this study. To obtain more creep curves within a short period and ensure the rock would be destroyed within stages $3-5$, the first load was approximately $65 \%-75 \%$ of the rock peak strength under corresponding conditions. Therefore, $70 \%$ of the triaxial compressive strength of the rock sample under the saturated condition was taken as the first-stage load, keeping the axial pressure constant and unloading the confining pressure; each level of confining pressure unloading was $\Delta \sigma_{3}=-3$ until final failure. The initial confining pressure was $20 \mathrm{MPa}$, and the axial compression was $70 \%$ of the peak strength of tuffaceous sandstone under different freeze-thaw cycles at 178, 166, 154, 134, and $120 \mathrm{MPa}$. 


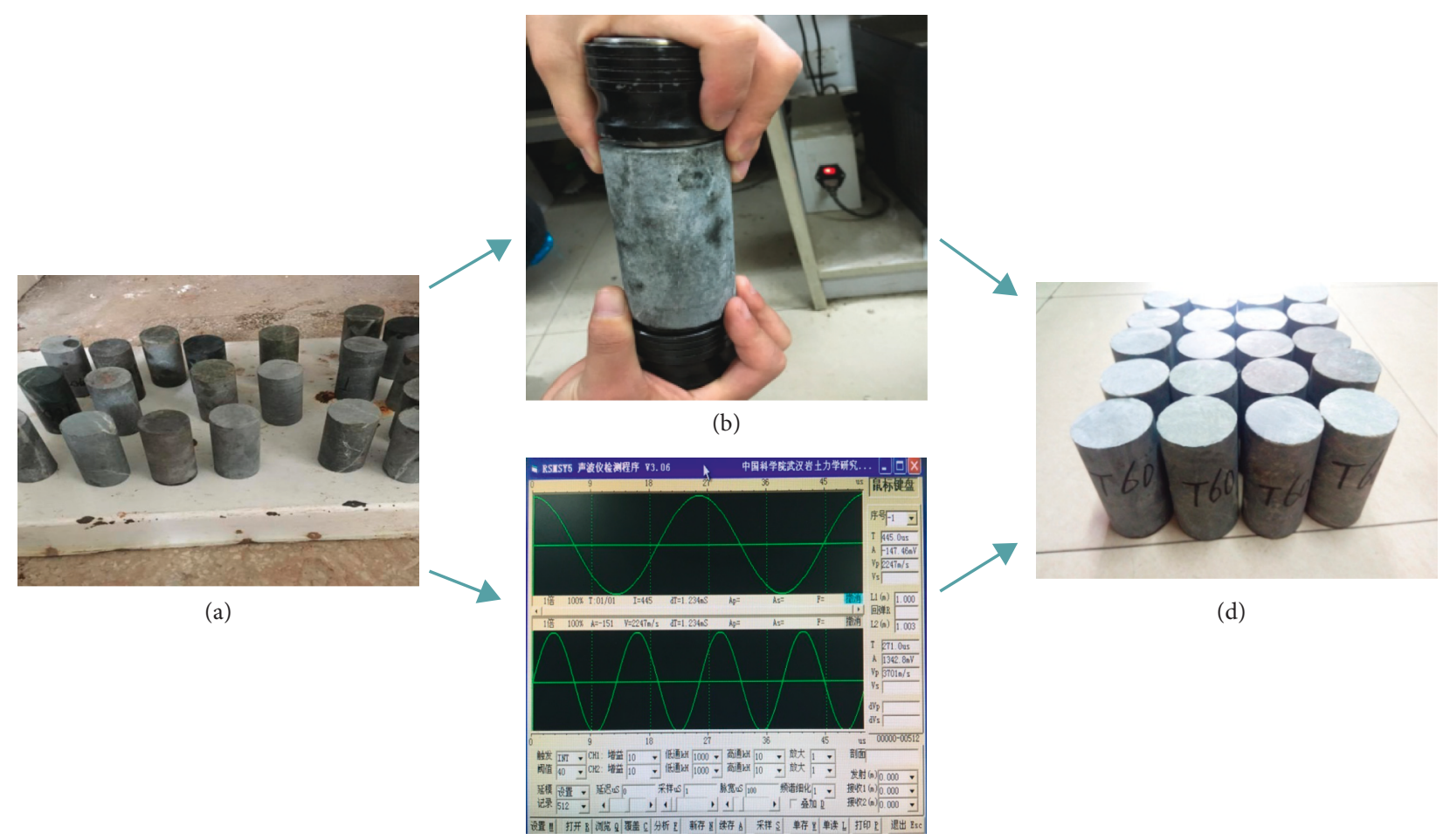

(c)

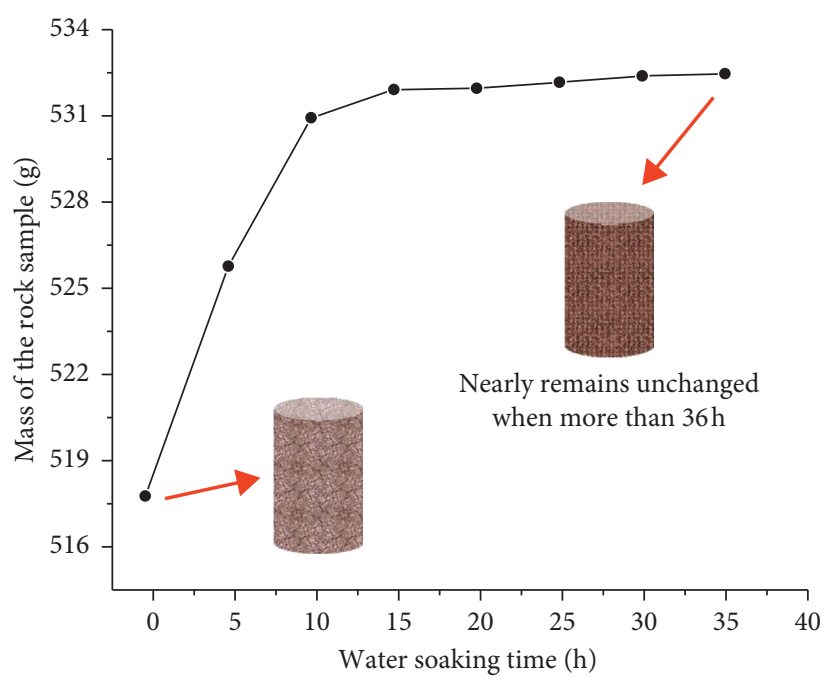

(e)

FIGURE 2: The process of sample screening: (a) cylindrical samples; (b) wave velocity induction transducer; (c) wave velocity test interface; (d) some screened samples; (e) variation of sample mass with soaking time in water.

\section{Results and Discussions}

3.1. Physical Properties of Rock Samples. The SEM and mass and wave velocity measurement results are shown in Figure 6 and Table 1. With an increase in freeze-thaw cycles, the $\mathrm{P}$-wave velocity of tuffaceous sandstone samples exhibited a downward trend, indicating that the samples had different degrees of deterioration after freeze-thaw cycles. After 60 freeze-thaw cycles, the reduction in wave velocity was $9.20 \%$, $9.48 \%, 6.11 \%, 5.18 \%$, and $13.17 \%$, respectively. The rock samples thus demonstrated varying extents of deterioration after freeze-thaw cycles. With an increase in freeze-thaw times, the development of micropores and cracks led to deterioration and damage to the internal structure of rock samples. The damage also resulted in rock looseness, which reduced sample compactness. Increased porosity allowed more water to enter the rock samples. The P-wave propagation velocity is faster in dense materials than loose materials and faster in solid materials than liquid materials; as such, the P-wave velocity in this study presented an overall downward trend.

The rate of reduction $\left(V_{\mathrm{P}}\right)$ in wave velocity was $2.23 \%$, $2.33 \%, 2.63 \%$, and $1.76 \%$ after $10,20,40$, and 60 freeze-thaw 


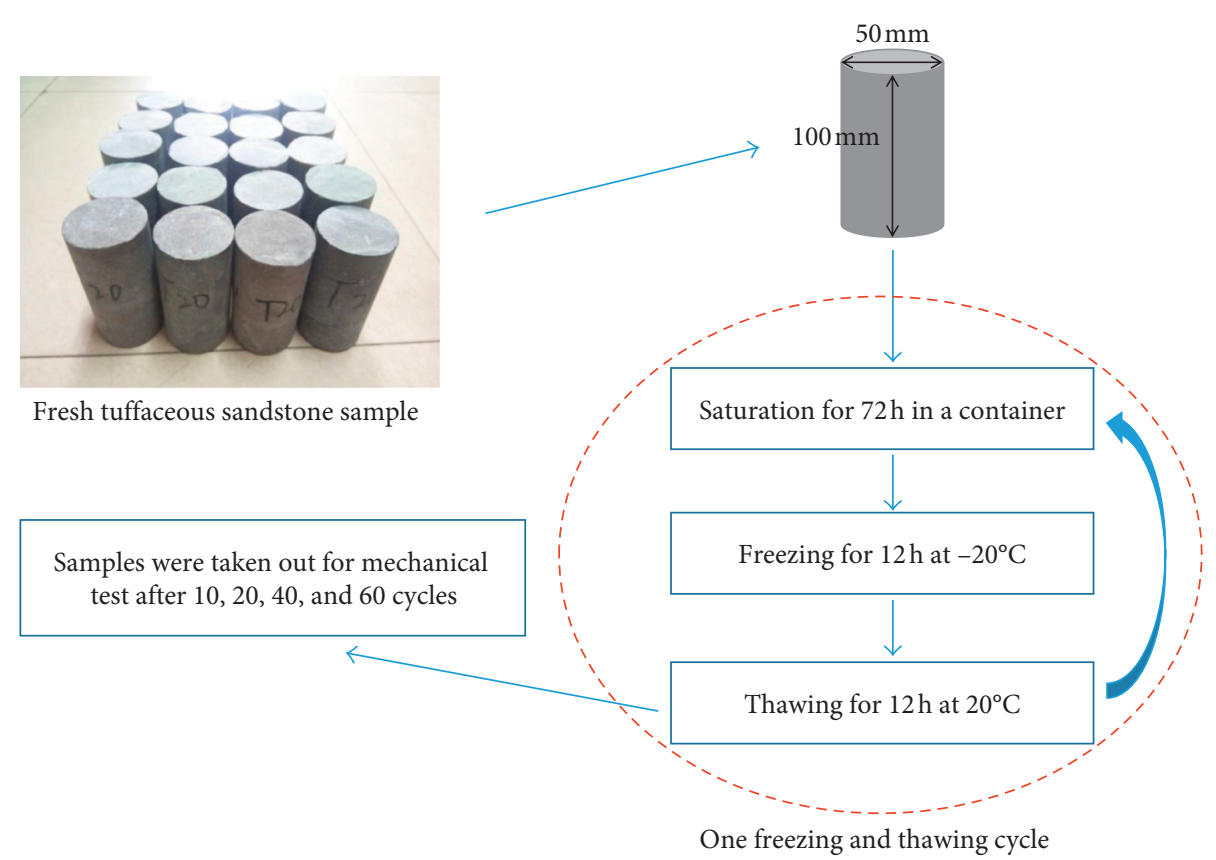

Figure 3: Experimental setup of freeze-thaw cycles.

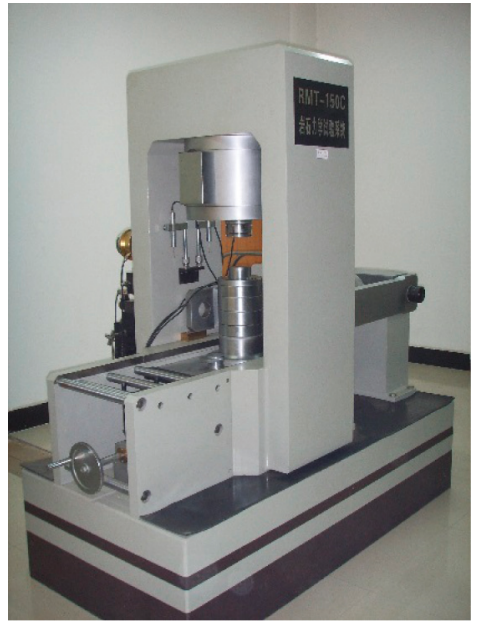

(a)

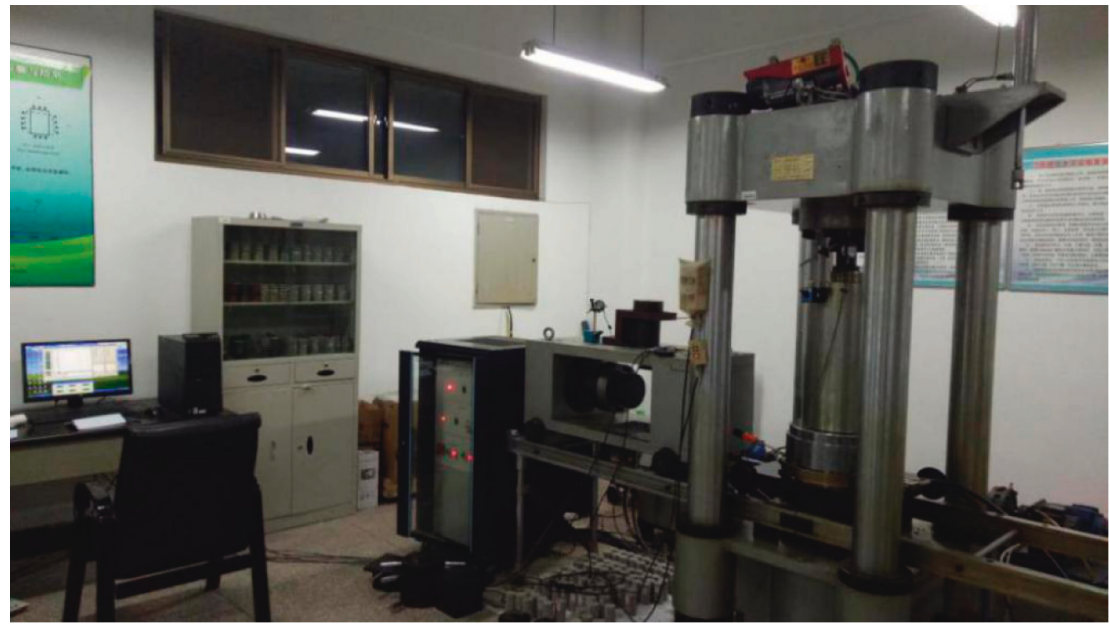

(b)

FIgURE 4: Mechanical testing instrument. (a) Triaxial apparatus (RMT-150). (b) Creep deformation apparatus (RLM-2000).

TABle 1: Physical parameters of tuffaceous sandstone samples under different freeze-thaw cycles.

\begin{tabular}{|c|c|c|c|c|c|c|}
\hline \multirow{2}{*}{ Wave velocity $(\mathrm{m} / \mathrm{s})$} & \multicolumn{6}{|c|}{ Times of freeze-thaw cycles } \\
\hline & $\mathrm{A}_{1}$ & $\mathrm{~A}_{2}$ & $\mathrm{~A}_{3}$ & $\mathrm{~A}_{4}$ & $\mathrm{~A}_{5}$ & $V_{\mathrm{P}}$ \\
\hline 0 & 4356.25 & 4536.68 & 4451.35 & 4287.56 & 4468.88 & 4420.144 \\
\hline 10 & 4298.64 & 4449.86 & 4386.62 & 4203.25 & 4270.05 & 4321.684 \\
\hline 20 & 4208.65 & 4320.52 & 4298.55 & 4126.38 & 4150.32 & 4220.884 \\
\hline 40 & 4115.24 & 4202.35 & 4167.68 & 4057.52 & 4007.38 & 4110.034 \\
\hline 60 & 3955.68 & 4106.78 & 4179.35 & 4065.45 & 3880.55 & 4037.562 \\
\hline Mass increment (g) & $A_{1}$ & $\mathrm{~A}_{2}$ & $\mathrm{~A}_{3}$ & $\mathrm{~A}_{4}$ & $\mathrm{~A}_{5}$ & $M$ \\
\hline 0 & 0 & 0 & 0 & 0 & 0 & 0 \\
\hline 10 & 1.46 & 0.97 & 1.29 & 1.01 & 2.31 & 1.41 \\
\hline 20 & 3.06 & 1.06 & 4.35 & 4.28 & 3.74 & 3.30 \\
\hline 40 & 9.48 & 4.97 & 9.96 & 9.24 & 7.53 & 8.24 \\
\hline 60 & 10.70 & 5.36 & 11.63 & 10.12 & 8.21 & 9.20 \\
\hline
\end{tabular}


cycles, respectively, exhibiting an initial increase followed by a decline because water entered the original crack in the rock sample, and the internal cracks expanded gradually during the initial freeze-thaw stage. However, with an increase in freeze-thaw time, fracture propagation was smaller than rock fracture in the early stage, moisture inflow was less than the initial inflow, deterioration of the rock samples tended to be stable, and the reduction in wave velocity gradually slowed.

Variations in rock mass after different freeze-thaw cycles are shown in Table 1. Rock sample mass increased after freeze-thaw cycles; after 60 cycles, the mass of rock samples in five groups increased by $10.7 \mathrm{~g}, 5.36 \mathrm{~g}, 11.63 \mathrm{~g}, 10.12 \mathrm{~g}$, and $8.21 \mathrm{~g}$, respectively. In addition, the change rate of rock mass shifted with an increase in freeze-thaw times (Figure 5). Due to differences in the samples, the mass change rates were different, but the average mass change rate exhibited an initial increase followed by a downward trend. After 40 freeze-thaw cycles, the rate of change reached a peak and then fell (Figure 5).

Main factors leading to variations in the mass of tuffaceous sandstone included changes in water quality and rock mineral quality. In this paper, each sample was thawed in water and remained in a saturated state.

When the number of freeze-thaw cycles was small, the temperature change resulted in a phase transition of pore water in the rock samples, and the shift in water volume evoked frost-heaving force between the diagenetic mineral particles. Therefore, microinterspaces within rock were constantly developed, expanded, and connected, rock porosity improved, and external moisture entered the rock, which increased the quality of the sample. Particle detachment, erosion, and spalling occurred on the rock surface due to the freeze-thaw cycle, resulting in reduced rock mass. However, when the number of freeze-thaw cycles was relatively small, the damage to the rock was lower, so the rock mass increased.

With an increase in freeze-thaw cycles, damage to the rock sample surface gradually increased, leading to a continuous decline in rock mass which exceeded the growing pore water quality; thus the mass of the rock sample declined slightly. Due to the limited number of freeze-thaw cycles in this paper, damage to the rock sample was limited, and the mass of rock samples increased overall. Presumably, with an increase in freeze-thaw times, more and more rock surface exfoliation will occur. Rock mass may be less than in samples that underwent no freeze-thaw cycles. The average mass change rate of rock samples will then tend to a stable value, and the change in pore water in rock samples should become balanced with the degree of rock surface damage.

The SEM results in Figure 6 indicate that the tuffaceous sandstone samples possessed better integrity, fewer internal cracks, and minimal micropores and microcracks before freeze-thaw cycles. Next, the structure of samples began to change; micropores developed and expanded before gradually becoming larger and connected. Microcracks then began to open, some started to connect, and particle cementation became weak; some particles broke away from their original positions and were scattered on the surface of the rock sample. Therefore, freeze-thaw cycles can affect the microstructure of tuffaceous sandstone and change the strength of rock by reducing the degree of cementation of mineral particles.

Two macroscopic failure modes emerged under freezethaw cycles: crack propagation and scaling (Figure 7). These two types of deterioration appeared simultaneously in the freeze-thaw test, but crack propagation was dominant. Tuffaceous sandstone is a brittle rock and contains fewer mineral particles with weak cementation. Under frostheaving force, some mineral grains spalled and precipitated near the end of the sample.

3.2. Analysis of Triaxial Test Results. According to the failure characteristics of tuffaceous sandstone under different freeze-thaw cycles at a confining pressure of $20 \mathrm{MPa}$, the rock samples presented shear failure. Grain spalling became obvious with an increase in freeze-thaw cycles, and a fracture surface developed from single to multiple fractures. Regarding the triaxial compression test, the stress-strain curves of tuffaceous sandstone under different freeze-thaw cycles and triaxial compression test parameters are illustrated in Figure 8 and Table 2. Triaxial compression stress-strain curves can be divided into a compression stage, elastic stage, yield stage, and failure stage. When the confining pressure was constant, the triaxial compressive strength declined with an increase in the number of freeze-thaw cycles. Based on rock deformation analysis, when the confining pressure was constant, strain deformation corresponding to the peak strength rose with an increase in freeze-thaw cycles (i.e., plasticity enhancement). When the number of freeze-thaw cycles was small, the effects of freezethaw cycles on the triaxial compression stress-strain curves of tuffaceous sandstone were not significant, indicating that freeze-thaw cycles had few effects on the mechanical properties of short-term loaded tuffaceous sandstone. Table 2 reveals that the peak strength, elastic modulus, cohesion, and internal friction angle of rock samples decreased with an increase in freeze-thaw times. The strain corresponding to the peak strength increased gradually at rates of $5.33 \%, 1.27 \%, 3.75 \%$, and $4.82 \%$, respectively.

3.3. Analysis of Creep Characteristics. Creep results of tuffaceous sandstone after different freeze-thaw cycles were obtained via experiment (Figure 9 and Table 3 ). The T10 rock samples of 10 freeze-thaw cycles (days) were destroyed after three unloading steps and four creep steps, whereas the remaining rock samples were destroyed after four unloading steps and five creep steps. Rock samples underwent $121.6 \mathrm{~h}$, $102.5 \mathrm{~h}, 118.3 \mathrm{~h}, 110.8 \mathrm{~h}$, and $109.0 \mathrm{~h}$ of creep deformation before failure, and the time of creep deformation to rock failure declined gradually.

Throughout the creep process, variations in the axial and radial creep of rock samples under freeze-thaw cycles were the same as those under non-freeze-thaw conditions. Compared with the non-freeze-thaw condition, instantaneous strain and creep strain under each stress level of freeze-thaw cycles increased slightly, indicating that the 


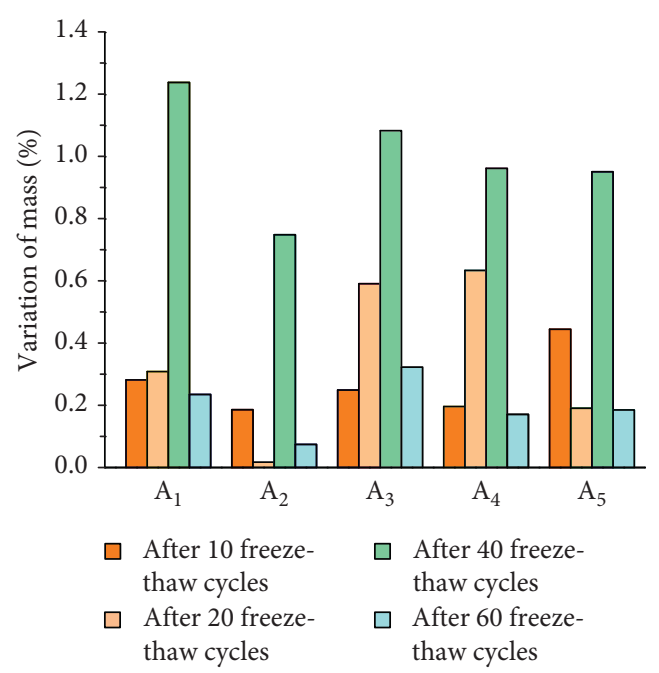

(a)

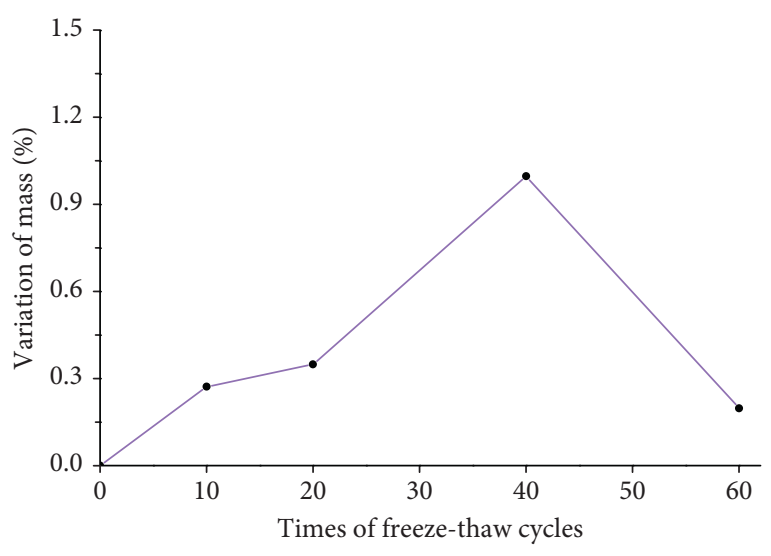

(b)

Figure 5: The variation of mass under different freeze-thaw cycles $(0,20,40$, and 60$)$.

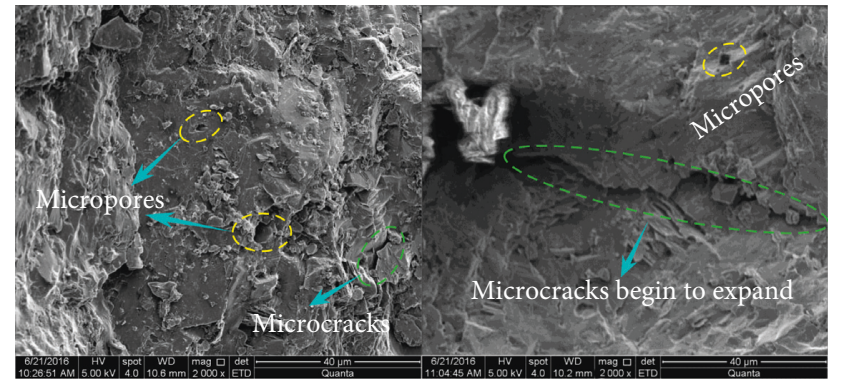

(a)

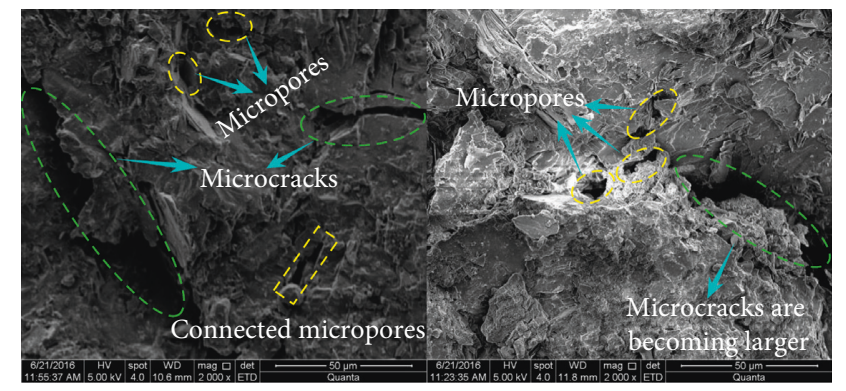

(b)

Figure 6: Scanning electron microscope of samples under different freeze-thaw cycles $(0,20,40$, and 60$)$.

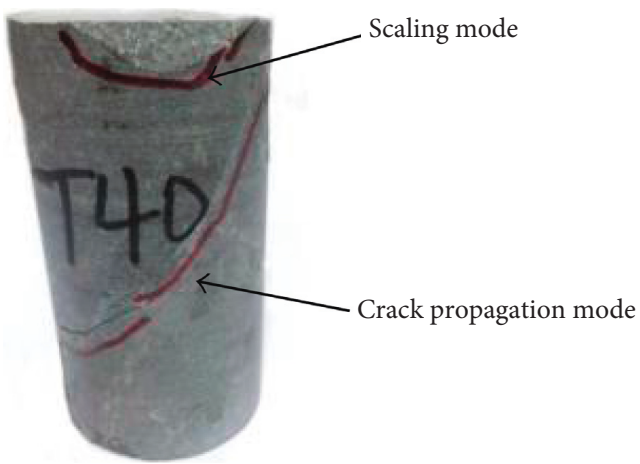

FIGURE 7: Failure modes of rock samples.

creep deformation of rock samples under freeze-thaw cycles improved.

The increase in radial creep deformation capacity was higher than that of axial creep deformation. For instantaneous and creep strain, axial strain exceeded radial strain under the first stress level. Axial creep strain remained relatively stable under the unloading process, whereas radial

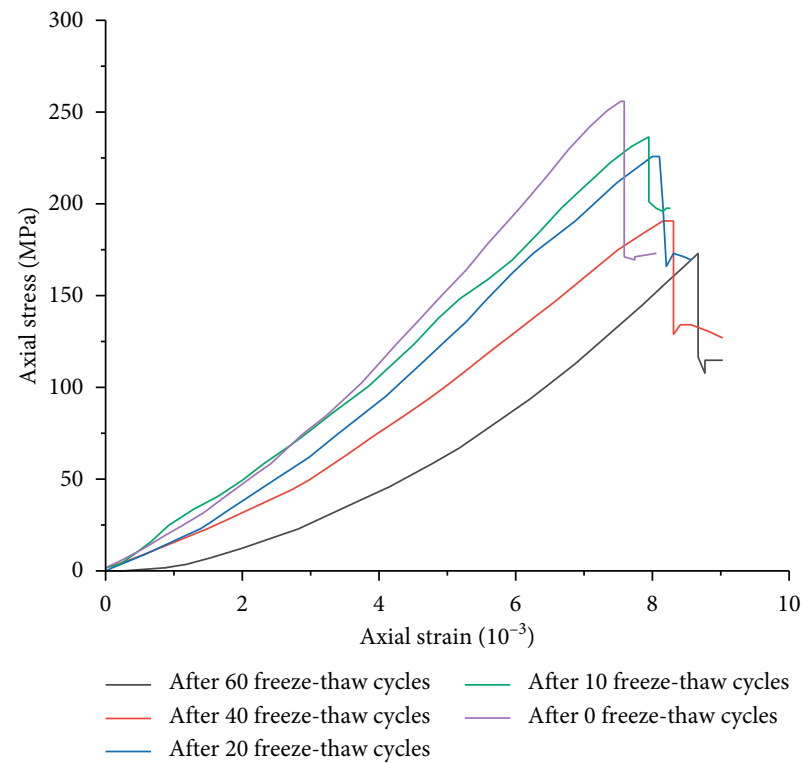

Figure 8: Stress-strain curves of the samples under different freezethaw cycles. 
TABLE 2: Three-dimensional axial compression test parameters of tuffaceous sandstone under different freeze-thaw cycles.

\begin{tabular}{lcccc}
\hline \multirow{2}{*}{ Parameter } & \multicolumn{3}{c}{ Times of freeze-thaw cycles } \\
& 0 & 10 & 20 & 40 \\
\hline Peak strength $(\mathrm{MPa})$ & 254.26 & 236.60 & 220.25 & 190.75 \\
Peak strain $\left(10^{-3}\right)$ & 7.5 & 7.9 & 8.0 & 8.3 \\
Elastic modulus $(\mathrm{GPa})$ & 42.5 & 37.9 & 36.5 & 8.7 \\
Cohesion $(\mathrm{MPa})$ & 275.45 & 255.43 & 246.64 & 34.6 \\
Internal friction angle (degrees) & 50.8 & 50.4 & 50.3 & 212.54 \\
\hline
\end{tabular}

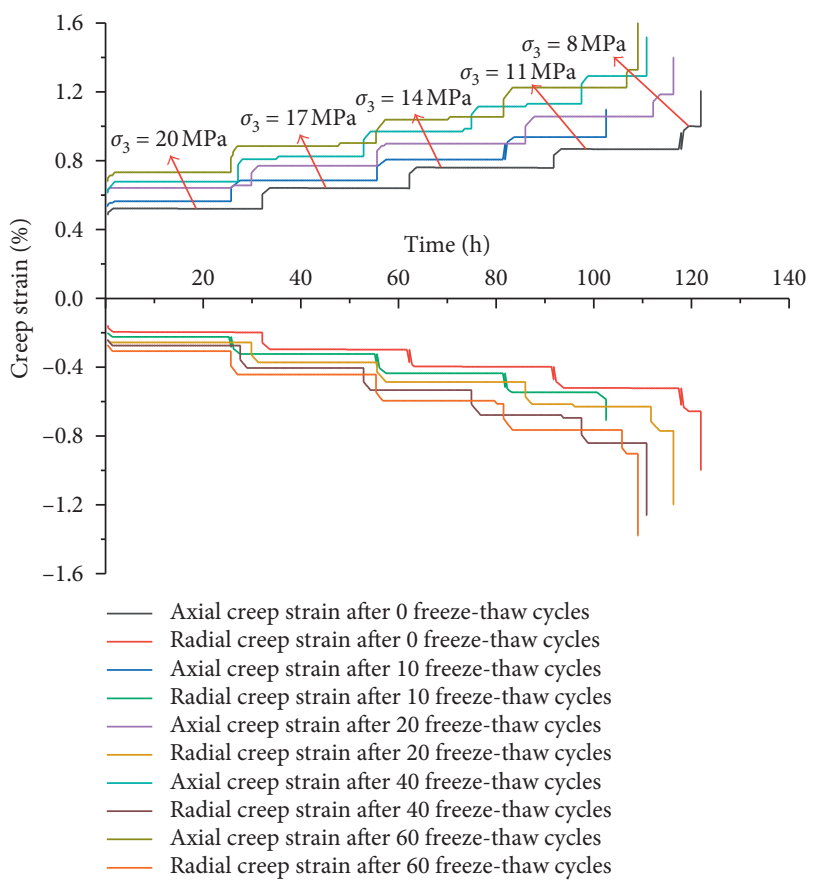

Figure 9: Creep curves under different freeze-thaw cycles.

creep strain continued increasing and even exceeded axial creep strain at the last stress level. Instantaneous strain and creep strain each increased in line with differential stress (differential stress $=\sigma_{1}-\sigma_{3}[49]$ ).

The reason is that confining pressure rendered the original pore and fissure compacted and in a closed state. At this time, axial strain dominated. With the unloading of confining pressure, differential stress increased and tension cracks occurred gradually in the rock. The expansion of tension cracks led to an increase in instantaneous strain, and microcracks developed gradually in the samples, indicating an increasing trend in radial creep.

\subsubsection{Sensitivity of Axial and Radial Creep. Differences} emerged in the unloading and loading creep tests, revealing that the laws of radial and axial creep differed. In this paper, axial and radial sensitivity during unloading were analyzed on the basis of the incremental ratio of radial and axial creep under different freeze-thaw cycles, and controllable aspects were identified for further study. Axial and radial deformation laws differed between unloading creep and compression creep. The relationship between the ratio of radial creep increment to axial creep increment and differential stress was statistically analyzed for tuffaceous sandstone under different freeze-thaw cycles.

Figure 10 shows that the sensitivity of axial and radial creep changes in rock samples without freeze-thaw cycles was consistent with that under freeze-thaw cycles. The ratio of radial creep to axial creep was less than 1 in the first stage of the unloading pressure creep test, suggesting that axial creep was dominant in the initial unloading stage and radial creep was secondary. However, in stepwise unloading, the ratio of radial creep to axial creep began to increase, the radial creep value exceeded axial creep, and the overall trend expanded. For the T0 rock sample, the creep ratio increased from 0.75 to $0.958,1.01,1.16$, and 1.26 , and radial expansion was apparent. The ratio of radial creep to axial creep was greater than 1, suggesting that radial creep was larger than axial creep. Damage from localized inhomogeneous failure during unloading was unclear but exerted a notable effect on radial creep.

When the differential stress was low, internal microcracks closed, and the deformation of the rock sample mainly involved axial compression. As differential stress increased, more microcracks were generated in the sample, and the radial dilatancy became more substantial. Deformation in the rock sample gradually transformed from axial compression to radial expansion, and the rate of radial creep was higher than that of axial creep. During the final unloading stage, the stress was higher than the yield stress, and the rock sample quickly entered an accelerated creep stage and broke down. The increment of radial creep was higher than that of axial creep, and the rate of radial creep was higher than that of axial creep before failure. Therefore, the radial direction was more sensitive to deformation and failure than the axial direction and played a pivotal role in failure and deformation. Radial creep often heavily influenced the unloading creep process for tuffaceous sandstone; that is, radial creep was more sensitive to the long-term load. Thus, the development law of radial creep strain warrants closer attention in practical engineering.

3.3.2. Volume Creep Properties. Based on results of the triaxial unloading creep test of tuffaceous sandstone, the volume expansion in this rock, as a hard and brittle material, occurred during the unloading creep process following freeze-thaw cycles. Volume strain can be used to predict rock mass failure; as such, it is important to study the characteristics of volume creep deformation in rock samples. Generally, volume strain cannot be measured directly by an instrument during testing but can be obtained by calculating 
TABLE 3: Triaxial unloading creep test results.

\begin{tabular}{|c|c|c|c|c|c|c|c|c|c|}
\hline \multirow[t]{2}{*}{ Samples } & \multirow[t]{2}{*}{$\sigma_{1}(\mathrm{MPa})$} & \multirow[t]{2}{*}{$\sigma_{3}(\mathrm{MPa})$} & \multirow[t]{2}{*}{ Differential stress $\sigma_{1}-\sigma_{3}(\mathrm{MPa})$} & \multicolumn{2}{|c|}{$\begin{array}{c}\text { Instantaneous } \\
\text { strain increment } \\
\left(10^{-2}\right)\end{array}$} & \multicolumn{2}{|c|}{$\begin{array}{c}\text { Creep strain } \\
\text { increment }\left(10^{-2}\right)\end{array}$} & \multicolumn{2}{|c|}{$\begin{array}{l}\text { Ratio of creep strain } \\
\text { increment to } \\
\text { instantaneous strain } \\
\text { increment (\%) }\end{array}$} \\
\hline & & & & Axial & Radial & Axial & Radial & Axial & Radial \\
\hline \multirow{5}{*}{ T0 specimen } & \multirow{5}{*}{178} & 20 & 158 & 0.4786 & -0.1516 & 0.0528 & -0.0396 & 11.0322 & 26.1214 \\
\hline & & 17 & 161 & 0.0786 & -0.0585 & 0.0425 & -0.0407 & 54.0712 & 69.5726 \\
\hline & & 14 & 164 & 0.0695 & -0.0653 & 0.0433 & -0.0437 & 62.3022 & 66.9219 \\
\hline & & 11 & 167 & 0.0737 & -0.0703 & 0.0470 & -0.0491 & 63.7720 & 69.8435 \\
\hline & & 8 & 170 & 0.0918 & -0.0878 & 0.0674 & -0.0788 & 73.4205 & 89.7494 \\
\hline \multirow{4}{*}{ T10 specimen } & \multirow{4}{*}{166} & 20 & 146 & 0.5114 & -0.1814 & 0.0553 & -0.0414 & 10.8135 & 22.8225 \\
\hline & & 17 & 149 & 0.0757 & -0.0597 & 0.0467 & -0.0452 & 61.6909 & 75.7112 \\
\hline & & 14 & 152 & 0.0764 & -0.0620 & 0.0477 & -0.0489 & 62.4346 & 78.8710 \\
\hline & & 11 & 155 & 0.0803 & -0.0773 & 0.0486 & -0.0923 & 60.5230 & 119.4049 \\
\hline \multirow{5}{*}{ T20 specimen } & \multirow{5}{*}{154} & 20 & 134 & 0.5907 & -0.2117 & 0.0617 & -0.0489 & 10.4452 & 23.0987 \\
\hline & & 17 & 137 & 0.0781 & -0.0574 & 0.0472 & -0.0497 & 60.4353 & 86.5854 \\
\hline & & 14 & 140 & 0.0820 & -0.0660 & 0.0533 & -0.0553 & 65.0000 & 83.7879 \\
\hline & & 11 & 143 & 0.0891 & -0.078 & 0.0563 & -0.0646 & 63.1874 & 82.8205 \\
\hline & & 8 & 146 & 0.0847 & -0.0864 & 0.0771 & -0.1076 & 91.0272 & 124.537 \\
\hline \multirow{5}{*}{ T40 specimen } & \multirow{5}{*}{134} & 20 & 114 & 0.6134 & -0.2244 & 0.0696 & -0.0537 & 11.3466 & 23.9605 \\
\hline & & 17 & 117 & 0.0849 & -0.0678 & 0.0638 & -0.0580 & 75.1472 & 85.5457 \\
\hline & & 14 & 120 & 0.0839 & -0.0717 & 0.0646 & -0.0618 & 76.9964 & 86.1925 \\
\hline & & 11 & 123 & 0.0843 & -0.0811 & 0.0712 & -0.0703 & 84.4603 & 86.6831 \\
\hline & & 8 & 126 & 0.0912 & -0.0853 & 0.1030 & -0.1268 & 112.9386 & 148.6518 \\
\hline \multirow{5}{*}{ T60 specimen } & \multirow{5}{*}{120} & 20 & 100 & 0.6630 & -0.2460 & 0.0678 & -0.0612 & 10.2262 & 24.8780 \\
\hline & & 17 & 103 & 0.0842 & -0.0708 & 0.0794 & -0.0683 & 94.2993 & 96.4689 \\
\hline & & 14 & 106 & 0.0866 & -0.0837 & 0.0742 & -0.0785 & 85.6813 & 93.7873 \\
\hline & & 11 & 109 & 0.0911 & -0.0929 & 0.0804 & -0.0812 & 88.2547 & 87.4058 \\
\hline & & 8 & 112 & 0.0958 & -0.0988 & 0.0928 & -0.1160 & 96.8685 & 117.4089 \\
\hline
\end{tabular}

measured data of axial strain and radial strain as shown in formula (1). Therefore, the volume creep-time curve of tuffaceous sandstone under different freeze-thaw cycles can be calculated as depicted in Figure 11. Variations in volume creep are presented in Table 4 . In terms of volume deformation, compression was positive and expansion was negative; a positive value indicates that the compression volume of the sample declined, whereas a negative value denotes an increase:

$$
\varepsilon_{v}=\varepsilon_{1}+2 \varepsilon_{3}
$$

where $\varepsilon_{1}$ is the axial creep and $\varepsilon_{3}$ is the radial creep.

The freeze-thaw times and differential stress level directly affected the axial and radial deformation of rock samples. Therefore, volume creep deformation characteristics can be analyzed based on freeze-thaw times and differential stress. First, with an increase in freeze-thaw cycles, the time required for specimens to be compressed and compacted declined overall. The compression time of the T0 specimen was $62 \mathrm{~h}$; the duration was $60.3 \mathrm{~h}$ for the T20 specimen, $58.8 \mathrm{~h}$ for the T40 specimen, and $56.7 \mathrm{~h}$ for the T60 specimen, after which the sample began to expand. Second, with an increase in differential stress, the increment of instantaneous strain shifted from positive to negative, and the instantaneous volume changed from a compaction state to an expansion state. Experimental data show that confining pressure can restrict volume creep, especially lateral creep.
Under unloading confining pressure, the rock began to exhibit damage and deterioration (i.e., dilatancy). Third, with an increase in freeze-thaw cycles, volume expansion became significant. For example, in the fourth step of the unloading process, the volume expansion capacity of rock samples increased from $-3.46 \times 10^{-3}$ for T0 to $-4.51 \times 10^{-3}$ for T20 and from $-5.12 \times 10^{-3}$ for T40 to $-5.67 \times 10^{-3}$ for T60. Freeze-thaw cycles therefore increased the volume expansion deformation of rock samples.

3.3.3. Preaccelerated Creep Rate Characteristics. The creep behavior of tuffaceous sandstone is similar to most geotechnical materials. Complete triaxial unloading creep curve of this material can be divided into three stages: deceleration creep, stable creep, and accelerated creep. This paper focused on the deceleration creep and stable creep stages without considering the accelerated creep stage. Generally, the rock sample enters accelerated creep when the strain reaches a threshold under the last confining pressure. At a confining pressure of $20 \mathrm{MPa}, 17 \mathrm{MPa}, 14 \mathrm{MPa}$, and $11 \mathrm{MPa}$ (except $11 \mathrm{MPa}$ for 10 freeze-thaw cycles), the specimens exhibited deceleration creep and stable creep (Figure 12). The creep rate reduced over time until reaching a stable value.

For the first four stress levels (T10 specimens demonstrated three stress levels), the rock creep rate changed suddenly at each unloading and resulted in large peak creep; then, the rate transitioned quickly to deceleration creep, 


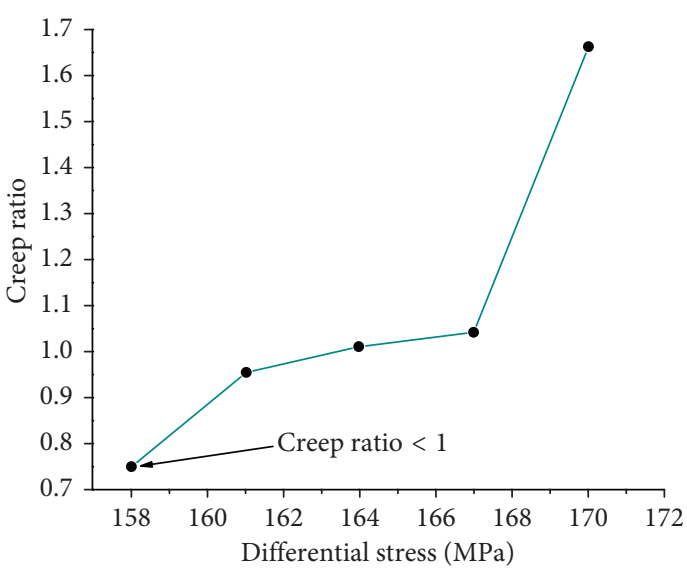

- T0 specimen

(a)

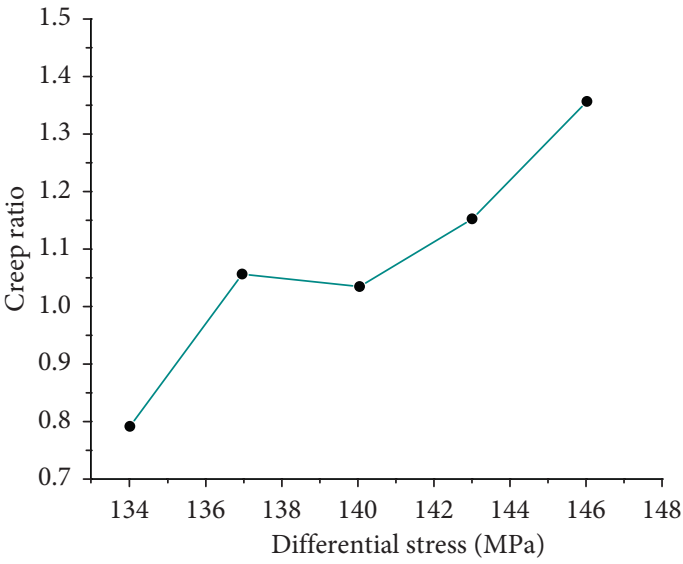

- T20 specimen

(c)

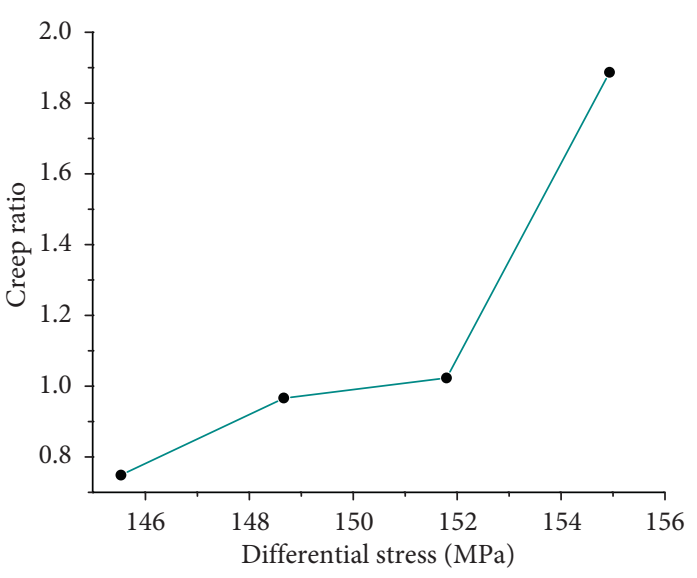

- T10 specimen

(b)

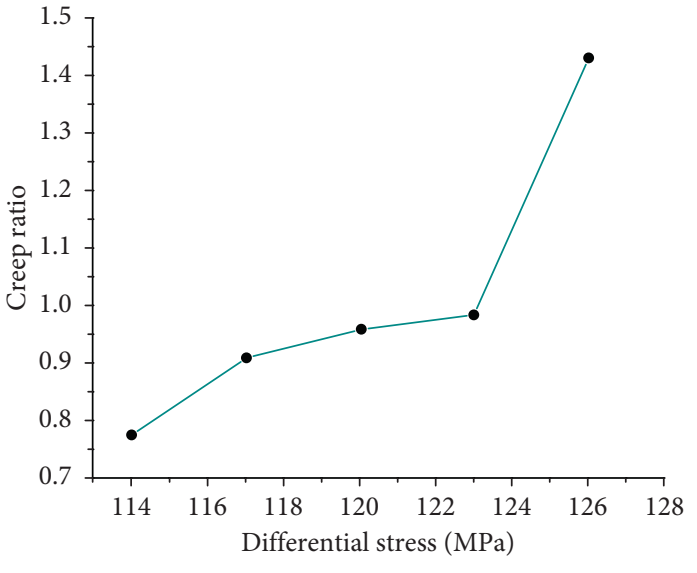

(d)

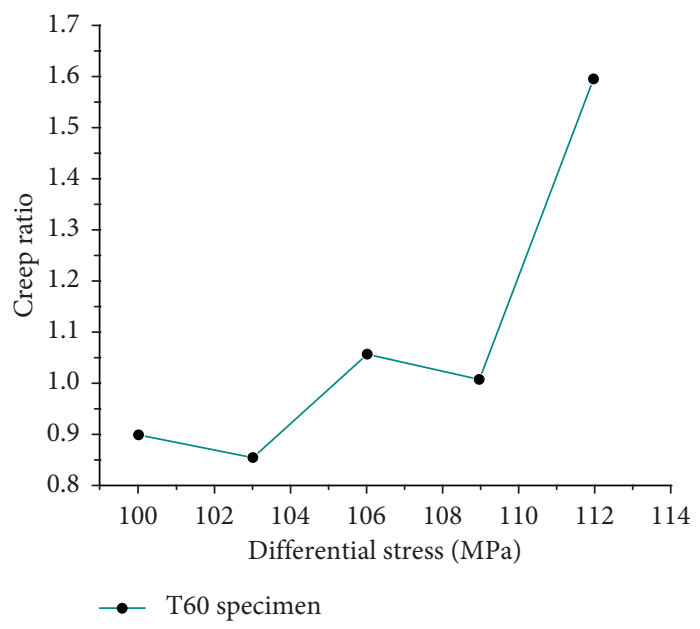

(e)

Figure 10: Variation of creep ratio $\left(\Delta \varepsilon_{3} / \Delta \varepsilon_{1}\right)$ with differential stress under different freeze-thaw cycles. (a) T0 specimen. (b) T10 specimen. (c) T20 specimen. (d) T40 specimen. (e) T60 specimen.

where the creep rate was inversely proportional to time before finally entering a stable creep stage. In the initial creep stage, creep variation exhibited growth over time, but the creep rate rapidly attenuated to a stable rate. After reaching stable creep, the creep rate increased with differential stress. The deceleration creep stage of this test lasted for 2-6h. Therefore, when excavating similar rock caverns, attention should be paid to deformation within a short time window 


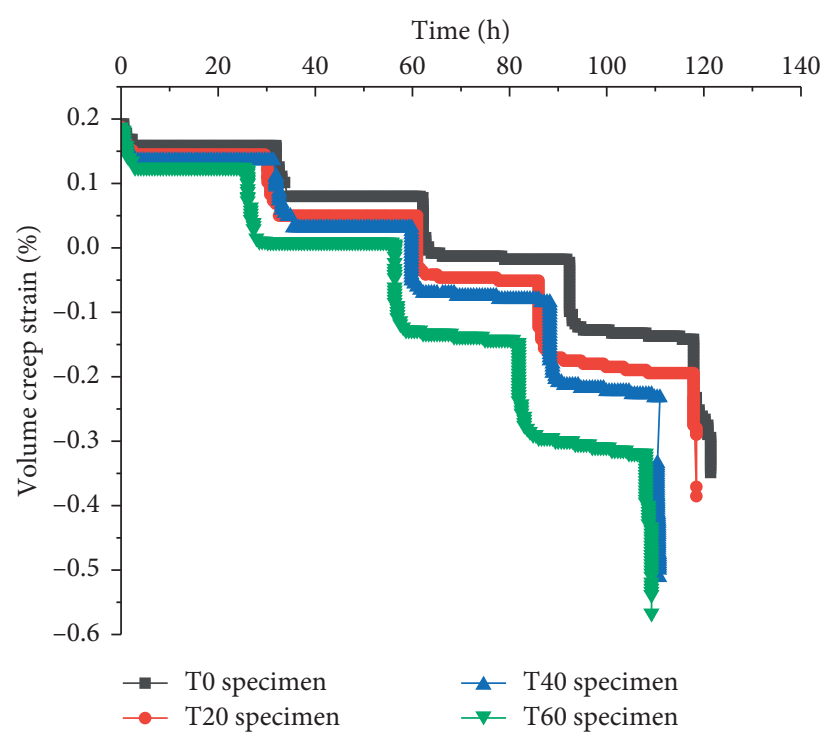

Figure 11: Volume creep-time curve.

TABLE 4: The variation of volume creep.

\begin{tabular}{|c|c|c|c|c|c|c|c|c|}
\hline \multirow[b]{2}{*}{$\begin{array}{l}\text { Stepwise } \\
\text { unloading }\end{array}$} & \multicolumn{2}{|c|}{ T0 specimen } & \multicolumn{2}{|c|}{ T20 specimen } & \multicolumn{2}{|c|}{ T40 specimen } & \multicolumn{2}{|c|}{ T60 specimen } \\
\hline & $\begin{array}{c}\text { Differential stress } \\
(\mathrm{MPa})\end{array}$ & $\begin{array}{c}\mathcal{E}_{\mathrm{v}} \\
\left(10^{-3}\right)\end{array}$ & $\begin{array}{c}\text { Differential stress } \\
(\mathrm{MPa})\end{array}$ & $\begin{array}{c}\mathcal{E}_{\mathrm{v}} \\
\left(10^{-3}\right)\end{array}$ & $\begin{array}{c}\text { Differential stress } \\
(\mathrm{MPa})\end{array}$ & $\begin{array}{c}\mathcal{E}_{\mathrm{v}} \\
\left(10^{-3}\right)\end{array}$ & $\begin{array}{c}\text { Differential stress } \\
(\mathrm{MPa})\end{array}$ & $\underset{\left(10^{-3}\right)}{\varepsilon_{\mathrm{v}}}$ \\
\hline $\begin{array}{l}\text { Initial state } \\
(20 \mathrm{MPa})\end{array}$ & 158 & 1.49 & 134 & 1.31 & 114 & 1.27 & 100 & 1.16 \\
\hline $\begin{array}{l}\text { First step } \\
(17 \mathrm{MPa})\end{array}$ & 161 & 0.72 & 137 & 0.42 & 117 & 0.24 & 103 & 0.02 \\
\hline $\begin{array}{l}\text { Second step } \\
(14 \mathrm{MPa})\end{array}$ & 164 & -0.34 & 140 & -0.65 & 120 & -0.94 & 106 & -1.62 \\
\hline $\begin{array}{l}\text { Third step } \\
(11 \mathrm{MPa})\end{array}$ & 167 & -1.52 & 143 & -2.05 & 123 & -2.42 & 109 & -3.39 \\
\hline $\begin{array}{l}\text { Fourth step } \\
(8 \mathrm{MPa})\end{array}$ & 170 & -3.46 & 146 & -4.51 & 126 & -5.12 & 112 & -5.67 \\
\hline
\end{tabular}

after excavation. During this period, the surrounding rock is often in the deceleration creep stage with rapid and extensive deformation, which can easily lead to engineering disasters.

In the stable creep stage, the rate of specimens remained essentially consistent with no large fluctuations. Throughout the creep process, stable creep constituted the main creep stage, which is important for the long-term strength of rock. The radial stable creep rates under different freeze-thaw cycles are listed in Table 5. The radial stable creep rate of samples increased gradually as confining pressure was unloaded (i.e., an increase in differential stress).

The peak creep rate increased with freeze-thaw times, as did the overall creep rate. For example, under $20 \mathrm{MPa}$ confining pressure, the radial stable creep rate increased after 10 , 20,40 , and 60 times to $0,71.43 \%, 85.71 \%$, and $128.6 \%$, respectively, compared with rock samples without freeze-thaw cycles. For specimens under the same freeze-thaw cycles, the creep rate increased with the unloading of surrounding pressure, suggesting that the unloading of confining pressure greatly influences rock stability. Confining pressure could reduce the creep rate of surrounding rock, and the rock sample did not exhibit substantial creep deformation and failure in this case. Therefore, during excavation and construction, necessary supporting and protection measures should be taken to reduce creep and improve the stability of the cavern for rock mass under three-dimensional stress to two-dimensional stress.

3.3.4. Long-Term Strength. According to the stable creep rate analysis, over time, the rock sample may become stable and reach an accelerated failure stage under different levels of differential stress. When stress was low, the stable creep rate was close to 0 , and axial compression played a prominent role in deformation. The axial creep rate was higher than the radial creep rate at this stage. With stepwise unloading, the differential stress and steady creep rate increased gradually, but the radial rate increased more rapidly than the axial rate, and deformation shifted gradually from axial to radial. Therefore, the axial and radial steady creep rates inevitably intersected. Before the intersection point, deformation of the rock sample was mainly elastic; beyond this intersection point, however, viscoplastic creep became dominant and the radial creep rate increased rapidly. Then, 


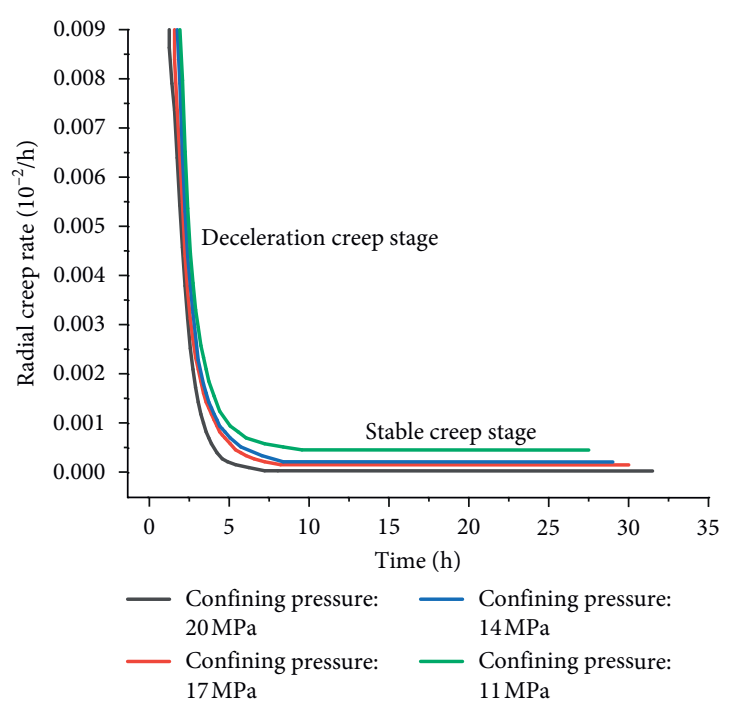

(a)

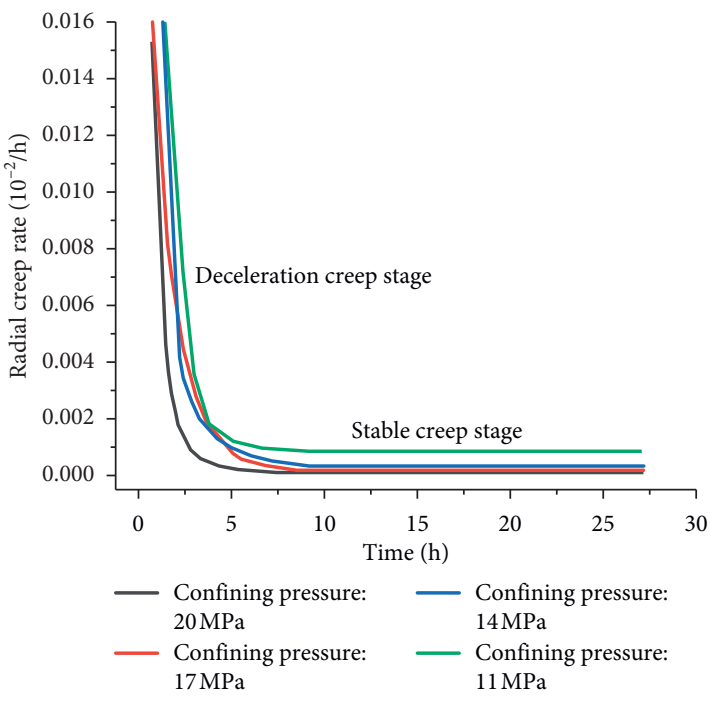

(c)

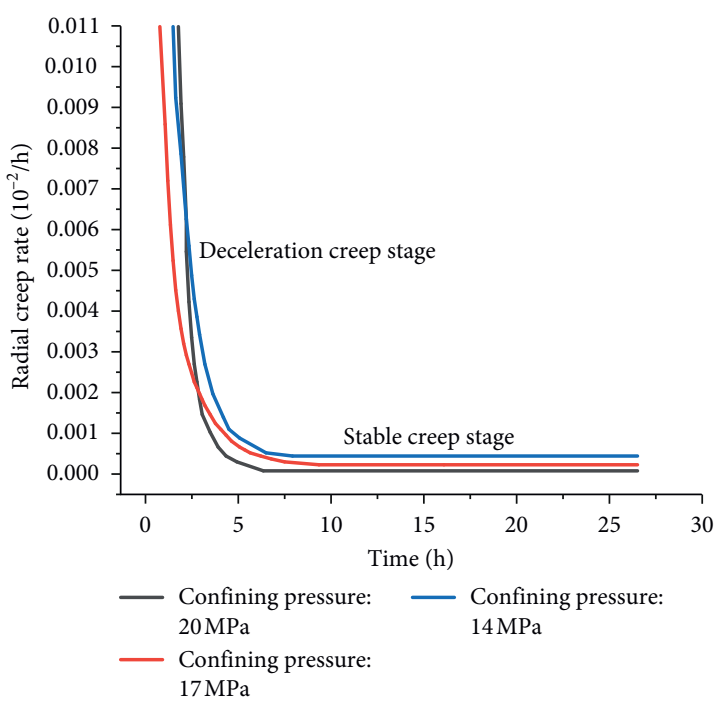

(b)

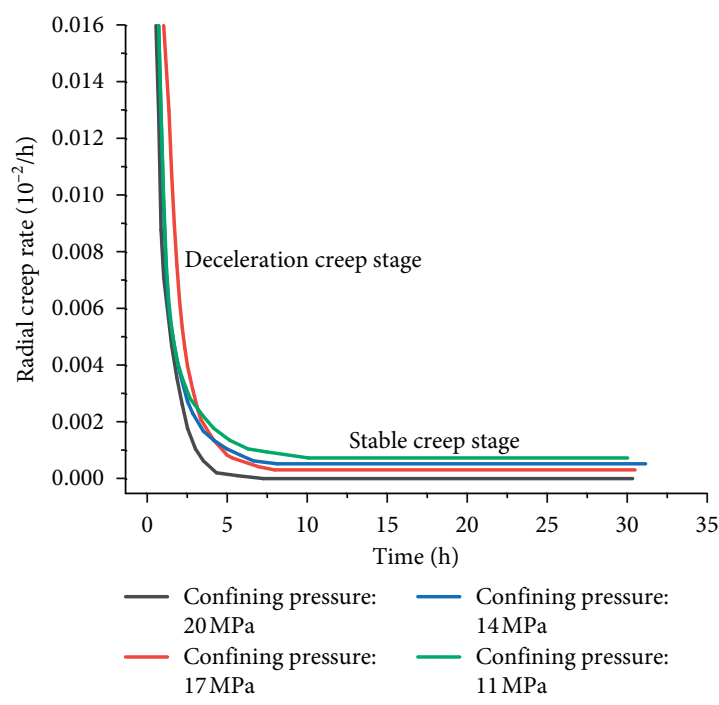

(d)

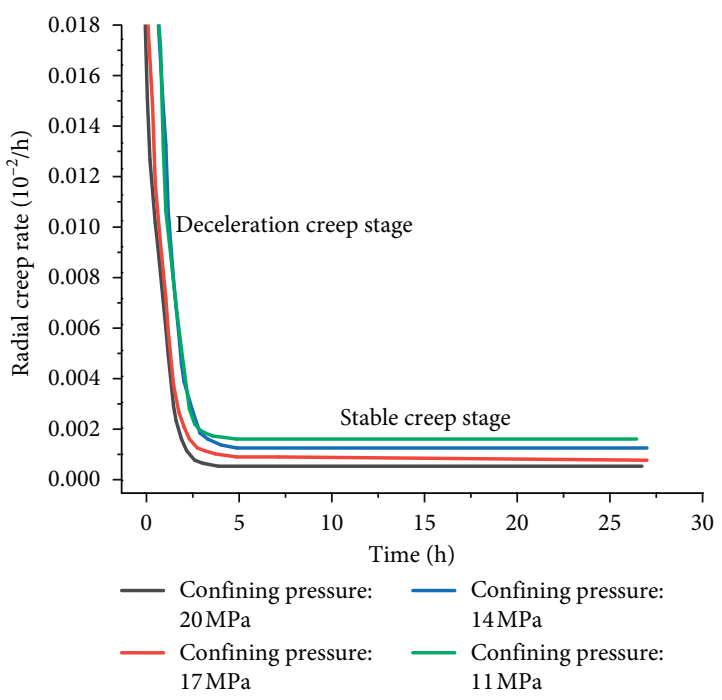

(e)

Figure 12: Radial creep rate under different freeze-thaw cycles. (a) T0 specimen. (b) T10 specimen. (c) T20 specimen. (d) T40 specimen. (e) T60 specimen. 
TABLE 5: Radial stable creep rate.

\begin{tabular}{lccccc}
\hline \multirow{2}{*}{ Confining pressure $(\mathrm{MPa})$} & \multicolumn{4}{c}{ Radial stable creep rate $\left(10^{-5} / \mathrm{h}\right)$} \\
& T0 specimen & T10 specimen & T20 specimen & T40 specimen & T60 specimen \\
\hline 20 & 0.07 & 0.07 & 0.12 & 0.13 & 0.16 \\
17 & 0.18 & 0.2 & 0.22 & 0.3 & 0.41 \\
14 & 0.28 & 0.38 & 0.4 & 0.85 & 0.88 \\
11 & 0.53 & - & 0.831 & 1.2 \\
\hline
\end{tabular}

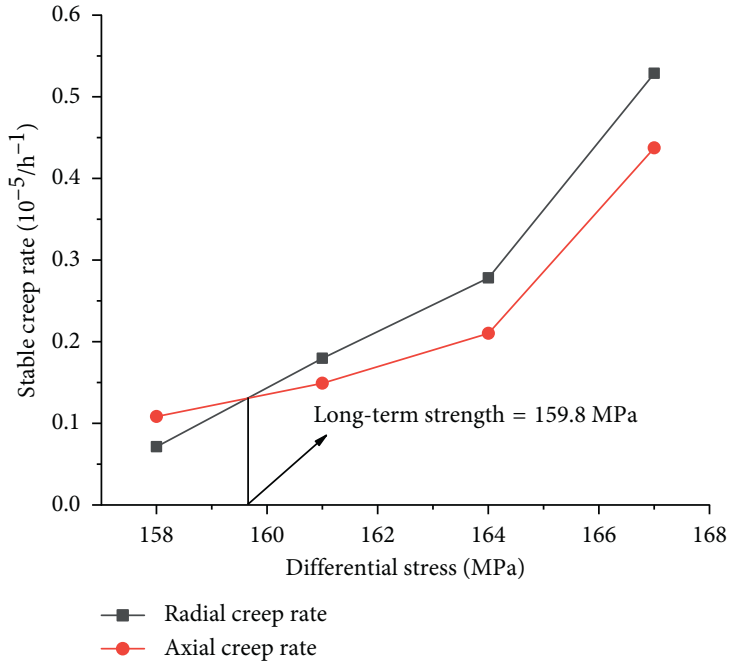

(a)

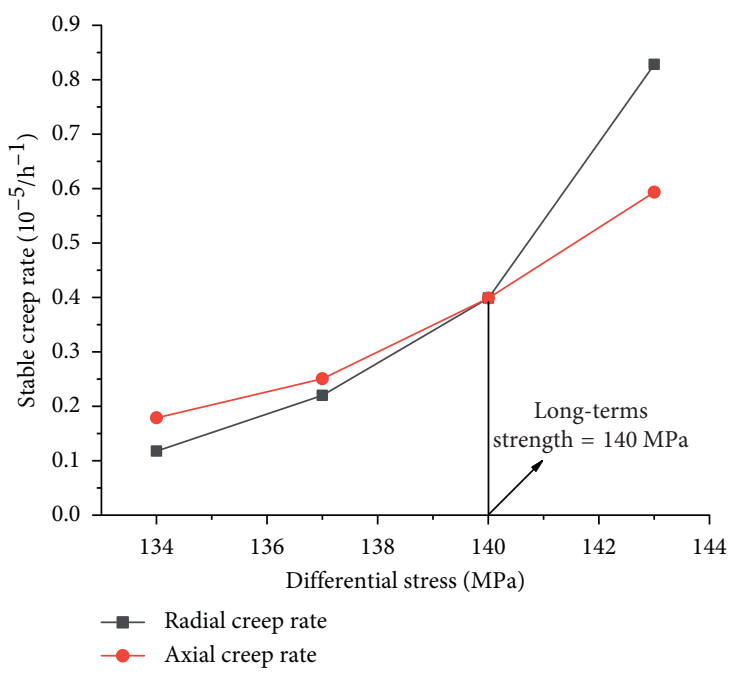

(c)

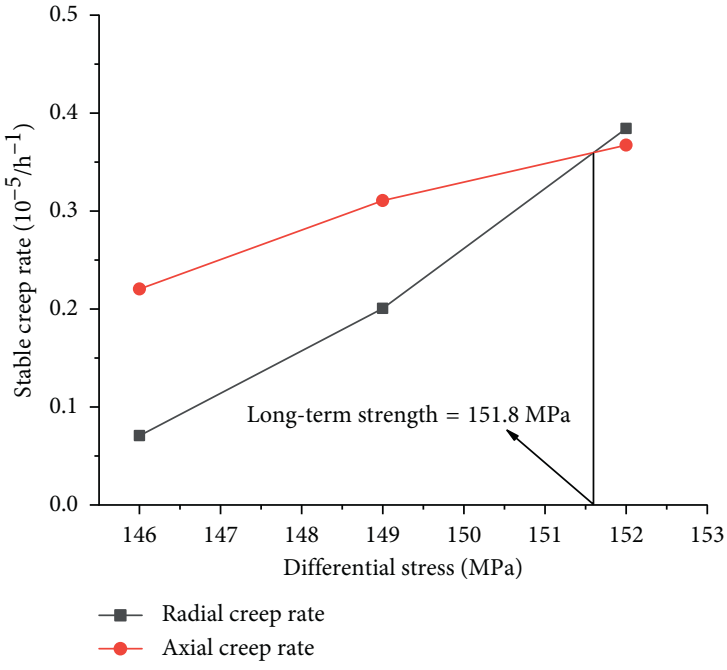

(b)

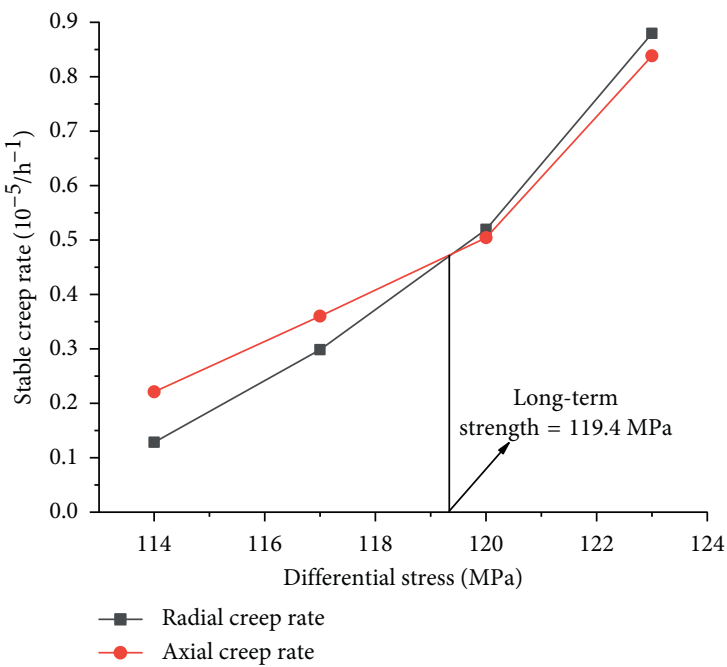

(d)

Figure 13: Continued. 


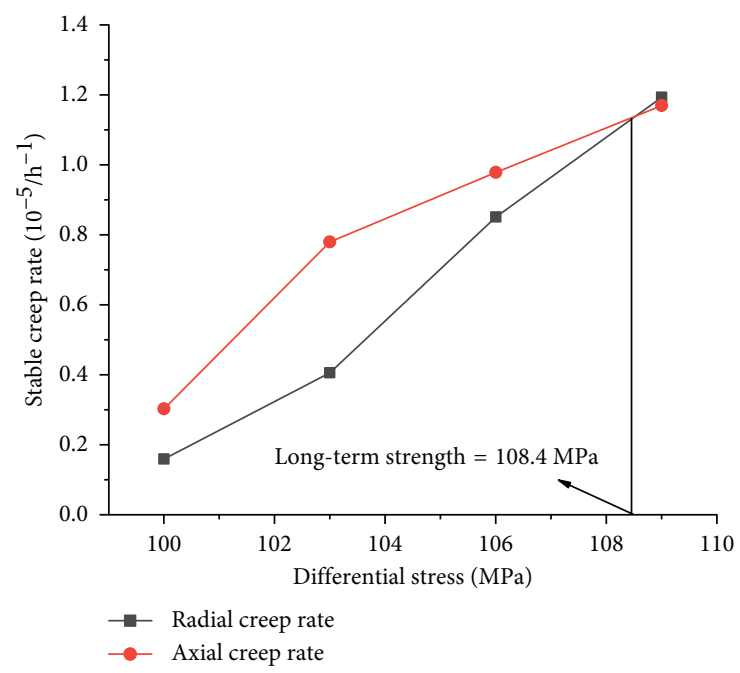

(e)

Figure 13: Stable creep rate-differential stress curve. (a) T0 specimen. (b) T10 specimen. (c) T20 specimen. (d) T40 specimen. (e) T60 specimen.

the specimens began to show clear radial dilatancy. Therefore, this point was defined as the near point of creep failure for tuffaceous sandstone, and its corresponding strength represents the long-term strength of rock [50-53]. In this paper, the stable creep intersection [50] was used to calculate and determine the long-term strength of rock considering axial and radial creep rates. The stable creep rate-differential stress curve is depicted in Figure 13.

The relationship between long-term strength and freezethaw cycles indicates that the long-term strength of tuffaceous sandstone declined with an increase in freeze-thaw cycles (Table 6). As the number of cycles increased, the longterm strength fell by $5.01 \%, 7.77 \%, 14.71 \%$, and $9.21 \%$, respectively. The long-term strength of tuffaceous sandstone reduced with growth in freeze-thaw cycles and then began to decline continuously.

\section{Conclusion}

In this paper, the physical and mechanical properties of tuffaceous sandstone were analyzed using freeze-thaw cycle tests, SEM, a triaxial compression test, and an unloading creep test. Experimental results show that freeze-thaw cycles heavily influence the creep properties of tuffaceous sandstone, which deserve closer attention in theory and practice. The main conclusions are as follows:

(1) When the number of freeze-thaw cycles was small, the quality of rock samples increased due to a lesser degree of damage. The reduction in wave velocity initially increased and then declined. The freezethaw cycle affected the microstructure of tuffaceous sandstone by reducing the degree of cementation of mineral particles and ultimately changing the rock strength. At a macroscopic level, the failure modes of rock samples were crack propagation mode and scaling mode.
TABLE 6: Long-term strength of tuffaceous sandstone.

\begin{tabular}{lccccc}
\hline Freeze-thaw cycles $(n)$ & 0 & 10 & 20 & 40 & 60 \\
\hline Long-term strength $(\mathrm{MPa})$ & 159.8 & 151.8 & 140 & 119.4 & 108.4 \\
\hline
\end{tabular}

(2) As freeze-thaw cycles increased, the cracking degree of tuffaceous sandstone was clear, and its peak strength, elastic modulus, cohesion, and internal friction angle decreased to varying degrees. Increases in peak strain were $5.33 \%, 1.27 \%, 3.75 \%$, and $4.82 \%$, respectively, suggesting that the mechanical properties of rock samples respond to freeze-thaw cycles.

(3) Under unloading conditions, the creep deformation of tuffaceous sandstone increased, and the enhancement of radial creep deformation was higher than that of axial creep deformation. As the number of freeze-thaw cycles grew, the creep deformation capacity increased first and then declined before becoming stable. Radial deformation was more sensitive to the deformation and failure of rock samples and played a dominant role in deformation and failure. Therefore, monitoring of radial deformation in tunnel confining pressure should be improved.

(4) In the preaccelerated creep stage of tuffaceous sandstone, stable creep was dominant. The deceleration creep stage of tuffaceous sandstone lasted for 2-6h during freeze-thaw cycles; thus, attention should be paid to deformation within a short time period. As the number of freeze-thaw cycles increased, the brittleness of tuffaceous sandstone declined and ductility increased. Unloading confining pressure exerted a substantial influence on rock stability, confining pressure could reduce the creep rate of surrounding rock, and the rock sample did not readily exhibit large creep deformation and failure. 
(5) The long-term strength reduction rates were 5.01\%, $7.77 \%, 14.71 \%$, and $9.21 \%$, respectively. With an increase in freeze-thaw cycles, the long-term strength of tuffaceous sandstone reduced continuously.

\section{Data Availability}

The data used to support the findings of this study are included within the article.

\section{Conflicts of Interest}

The authors declare that there are no conflicts of interest regarding the publication of this paper.

\section{Acknowledgments}

This work was financially supported by the National Key R\&D Program of China (no. 2018YFC0808706).

\section{References}

[1] J. Lai, X. Wang, J. Qiu, J. Chen, Z. Hu, and H. Wang, "Extreme deformation characteristics and countermeasures for a tunnel in difficult grounds in southern Shaanxi, China," Environmental Earth Sciences, vol. 77, no. 706, 2018.

[2] Z. Wang, Z. Hu, J. Lai, H. Wang, K. Wang, and W. Zan, "Settlement characteristics of jacked box tunneling underneath a highway embankment," Journal of Performance of Constructed Facilities, vol. 33, no. 2, article 04019005, 2019.

[3] J. Lai, K. Wang, J. Qiu, F. Niu, J. Wang, and J. Chen, "Vibration response characteristics of the cross tunnel structure," Shock and Vibration, vol. 2016, Article ID 9524206, 16 pages, 2016.

[4] Y. Li, S. Xu, H. Liu, E. Ma, and L. Wang, "Displacement and stress characteristics of tunnel foundation in collapsible loess ground reinforced by jet grouting columns," Advances in Civil Engineering, vol. 2018, Article ID 2352174, 16 pages, 2018.

[5] X. Luo, D. Li, Y. Yang, and S. Zhang, "Spatiotemporal traffic flow prediction with KNN and LSTM," Journal of Advanced Transportation, vol. 2019, Article ID 4145353, 10 pages, 2019.

[6] T.-J. Zhang, M.-A. Parsons, and R.-G. Barry, "Statistic of global permafrost distribution," in Proceedings of Asian Conference on Permafrost, pp. 7-8, Lanzhou, China, August 2006.

[7] Y. Lai, X. Xu, Y. Dong, and S. Li, "Present situation and prospect of mechanical research on frozen soils in China," Cold Regions Science and Technology, vol. 87, pp. 6-18, 2013.

[8] Z. Hu, H. Ding, J. Lai, H. Wang, X. Wang, and S. He, "The durability of shotcrete in cold region tunnel: a review," Construction and Building Materials, vol. 185, pp. 670-683, 2018.

[9] D. Chang and J.-K. Liu, "Review of the influence of freezethaw cycles on the physical and mechanical properties of soil," Sciences in Cold and Arid Regions, vol. 5, no. 4, pp. 457-460, 2013.

[10] J. Lai, J. Qiu, H. Fan et al., "Fiber bragg grating sensors-based in-situ monitoring and safety assessment of loess tunnel," Journal of Sensors, vol. 2016, Article ID 8658290, 10 pages, 2016.

[11] J. Lai, S. He, J. Qiu et al., "Characteristics of seismic disasters and aseismic measures of tunnels in wenchuan earthquake," Environmental Earth Sciences, vol. 76, p. 94, 2017.
[12] J. Lai, X. Wang, J. Qiu et al., "A state-of-the-art review of sustainable energy based freeze proof technology for coldregion tunnels in China," Renewable and Sustainable Energy Reviews, vol. 82, pp. 3554-3569, 2018.

[13] J. Lai, J. Qiu, H. Fan, J. Chen, and Y. Xie, "Freeze-proof method and test verification of a cold region tunnel employing electric heat tracing," Tunnelling and Underground Space Technology, vol. 60, pp. 56-65, 2016.

[14] J.-X. Lai, J.-L. Qiu, J.-X. Chen, H. Fan, and K. Wang, "New technology and experimental study on snow-melting heated pavement system in tunnel portal," Advances in Materials Science and Engineering, vol. 2015, Article ID 706536, 11 pages, 2015.

[15] W. Lee, N. C. Bohra, A. G. Altschaeffl, and T. D. White, "Resilient modulus of cohesive soils and the effect of freezethaw," Canadian Geotechnical Journal, vol. 32, no. 4, pp. 559-568, 1995.

[16] T. C. Johnson, D. M. Cole, and E. J. Chamberlain, "Effect of freeze-thaw cycles on resilient properties of fine-grained soils," Developments in Geotechnical Engineering, vol. 13, pp. 247-276, 1979.

[17] Y. Lai, L. Jin, and X. Chang, "Yield criterion and elasto-plastic damage constitutive model for frozen sandy soil," International Journal of Plasticity, vol. 25, no. 6, pp. 1177-1205, 2009.

[18] S.-B. Xie, Q. Jian-jun, L. Yuan-ming, Z. Zhi-wei, and X. Xiang-tian, "Effects of freeze-thaw cycles on soil mechanical and physical properties in the Qinghai-Tibet Plateau," Journal of Mountain Science, vol. 12, no. 4, pp. 999-1009, 2015.

[19] Z. Yang, B. Still, and X. Ge, "Mechanical properties of seasonally frozen and permafrost soils at high strain rate," Cold Regions Science and Technology, vol. 113, pp. 12-19, 2015.

[20] Z.-D. Cui, P.-P. He, and W.-H. Yang, "Mechanical properties of a silty clay subjected to freezing-thawing," Cold Regions Science and Technology, vol. 98, pp. 26-34, 2014.

[21] Z.-W. Zhou, W. Ma, S.-J. Zhang, Y. Mu, and G. Li, "Effect of freeze-thaw cycles in mechanical behaviors of frozen loess," Cold Regions Science and Technology, vol. 146, pp. 9-18, 2018.

[22] B. Paudel and B. Wang, "Freeze-thaw effect on consolidation properties of fine grained soil from the Mackenzie Valley," Canadian Geographical Society, vol. 2010, pp. 992-996, 2010.

[23] T.-L. Wang, Y.-J. Liu, H. Yan, and L. Xu, “An experimental study on the mechanical properties of silty soils under repeated freeze-thaw cycles," Cold Regions Science and Technology, vol. 112, pp. 51-65, 2015.

[24] M. E. Orakoglu and J. Liu, "Effect of freeze-thaw cycles on triaxial strength properties of fiber-reinforced clayey soil," KSCE Journal of Civil Engineering, vol. 21, no. 6, pp. 21282140, 2017.

[25] W. Ma, G.-D. Cheng, and Q.-B. Wu, "Construction on permafrost foundations: lessons learned from the QinghaiTibet railroad," Cold Regions Science and Technology, vol. 59, no. 1, pp. 3-11, 2009.

[26] X.-J. Tan, "Study on the mechanism of frost heave of tunnel in cold region with high altitude and related insulation technology," Ph.D. thesis, Chinese Academy of Science, Beijing, China, 2010, in Chinese.

[27] Z. Zhou, C. Ren, G. Xu, H. Zhan, and T. Liu, "Dynamic failure mode and dynamic response of high slope using shaking table test," Shock and Vibration, vol. 2019, Article ID 4802740, 19 pages, 2019.

[28] Z. J. Zhou, S. S. Zhu, X. Kong, J. T. Lei, and T. Liu, "Optimization analysis of settlement parameters for post-grouting 
piles in loess area of Shaanxi, China," Advances in Civil Engineering, vol. 2019, Article ID 7085104, 16 pages, 2019.

[29] A. Prick, "Dilatometrical behaviour of porous calcareous rock samples subjected to freeze-thaw cycles," Catena, vol. 25, no. 1-4, pp. 7-20, 1995.

[30] B. D. Fahey, "Frost action and hydration as rock weathering mechanisms on schist: a laboratory study," Earth Surface Processes and Landforms, vol. 8, no. 6, pp. 535-545, 1983.

[31] N. Matsuoka, "Mechanisms of rock breakdown by frost action: an experimental approach," Cold Regions Science and Technology, vol. 17, no. 3, pp. 253-270, 1990.

[32] V.-G. Ruiz, R.-A. Rey, C. Clorio et al., "Characterization by computed X-ray tomography of the evolution of the pore structure of a dolomite rock during freeze-thaw cyclic test," Physics and Chemistry of the Earth, Part A: Solid Earth and Geodesy, vol. 24, no. 7, pp. 633-637, 1999.

[33] D. T. Nicholson and F. H. Nicholson, "Physical deterioration of sedimentary rocks subjected to experimental freeze-thaw weathering," Earth Surface processes and Landforms, vol. 25, no. 12, pp. 1295-1307, 2000.

[34] T. Yamabe and K. M. Neaupane, "Determination of some thermo-mechanical properties of Sirahama sandstone under subzero temperature condition," International Journal of Rock Mechanics and Mining Sciences, vol. 38, no. 7, pp. 1029-1034, 2001.

[35] H. Yavuz, "Effect of freeze-thaw and thermal shock weathering on the physical and mechanical properties of an andesite stone," Bulletin of Engineering Geology and the Environment, vol. 70, no. 2, pp. 187-192, 2011.

[36] F. Bayram, "Predicting mechanical strength loss of natural stones after freeze-thaw in cold regions," Cold Regions Science and Technology, vol. 83-84, pp. 98-102, 2012.

[37] H. Zhang, Z. Wang, Y. Zheng, P. Duan, and S. Ding, "Study on tri-axial creep experiment and constitutive relation of different rock salt," Safety Science, vol. 50, no. 4, pp. 801-805, 2012.

[38] S.-Q. Yang, H.-W. Jing, and L. Cheng, "Influences of pore pressure on short-term and creep mechanical behavior of red sandstone," Engineering Geology, vol. 179, pp. 10-23, 2014.

[39] X. Zhao and G. Zhou, "Experimental study on the creep behavior of frozen clay with thermal gradient," Cold Regions Science and Technology, vol. 86, pp. 127-132, 2013.

[40] G.-Q. Chen, F. Guo, J.-C. Wang et al., "Experimental study of creep properties of quartz sandstone after freezing-thawing cycles," Rock and Soil Mechanics, vol. 38, no. S1, pp. 203-210, 2017, in Chinese.

[41] H. Jia, W. Xiang, and M. Krautblatter, "Quantifying rock fatigue and decreasing compressive and tensile strength after repeated freeze-thaw cycles," Permafrost and Periglacial Processes, vol. 26, no. 4, pp. 368-377, 2015.

[42] X. Huang, Q.-S. Liu, Y.-S. Kang et al., "Triaxial unloading creep experimental study of sandy mudstone," Chinese Journal of Rock Mechanics and Engineering, vol. 35, no. S1, pp. 2651-2662, 2016, in Chinese.

[43] Z. Papay and A. Torok, "Effect of thermal and freeze-thaw stress on the mechanical properties of porous limestone," Periodica Polytechnica-Civil Engineering, vol. 62, no. 2, pp. 423-428, 2018.

[44] Y.-G. Yang, Y.-M. Lai, and X.-X. Chang, "Experimental and theoretical studies on the creep behavior of warm ice-rich frozen sand," Cold Regions Science and Technology, vol. 63, no. 1-2, pp. 61-67, 2010.

[45] R. Ren, S. Xu, Z. Ren et al., "Numerical investigation of particle concentration distribution characteristics in twin- tunnel complementary ventilation system," Mathematical Problems in Engineering, vol. 2018, Article ID 1329187, 13 pages, 2018.

[46] Z. Zhang, H. Zhang, Y. Tan, and H. Yang, "Natural wind utilization in the vertical shaft of a super-long highway tunnel and its energy saving effect," Building and Environment, vol. 145, pp. 140-152, 2018.

[47] X. Li, X. Qu, C. Qi, and Z. Shao, "A unified analytical method calculating brittle rocks deformation induced by crack growth," International Journal of Rock Mechanics and Mining Sciences, vol. 113, pp. 134-141, 2019.

[48] J. Lai, S. Mao, J. Qiu et al., "Investigation progresses and applications of fractional derivative model in geotechnical engineering," Mathematical Problems in Engineering, vol. 2016, Article ID 9183296, 15 pages, 2016.

[49] T. Engelder, "Deviatoric stressitis: a virus infecting the Earth science community," Eos, Transactions American Geophysical Union, vol. 75, no. 18, pp. 209-216, 1994.

[50] Y. Zhang, P.-J. Jin, W.-Y. Xu et al., "Experimental study of triaxial creep behavior and long-term strength of clastic rock in dam foundation," Rock and Soil Mechanics, vol. 37, no. 5, pp. 1291-1301, 2016, in Chinese.

[51] L. Duan, Y. Zhang, and J. Lai, "Influence of ground temperature on shotcrete-to-rock adhesion in tunnels: a review," Advances in Materials Science and Engineering, vol. 2019, Article ID 8709087, 12 pages, 2019.

[52] L. Duan, W. Lin, J. Lai, and P. Zhang, "Vibration characteristic of high-voltage tower influenced by adjacent tunnel blasting construction," Shock and Vibration, vol. 2019, Article ID 8520564, 16 pages, 2019.

[53] X. Wang, J. Lai, and R. Garnes, "On the support system for tunnelling in squeezing ground of Qingling-Daba mountainous area: case study from soft rock tunnels," Advances in Civil Engineering, vol. 2019, Article ID 8682535, 12 pages, 2019. 


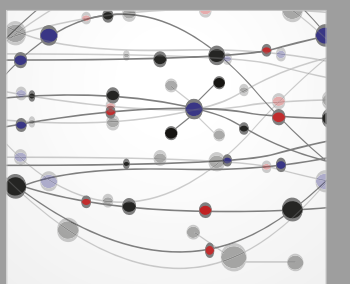

The Scientific World Journal
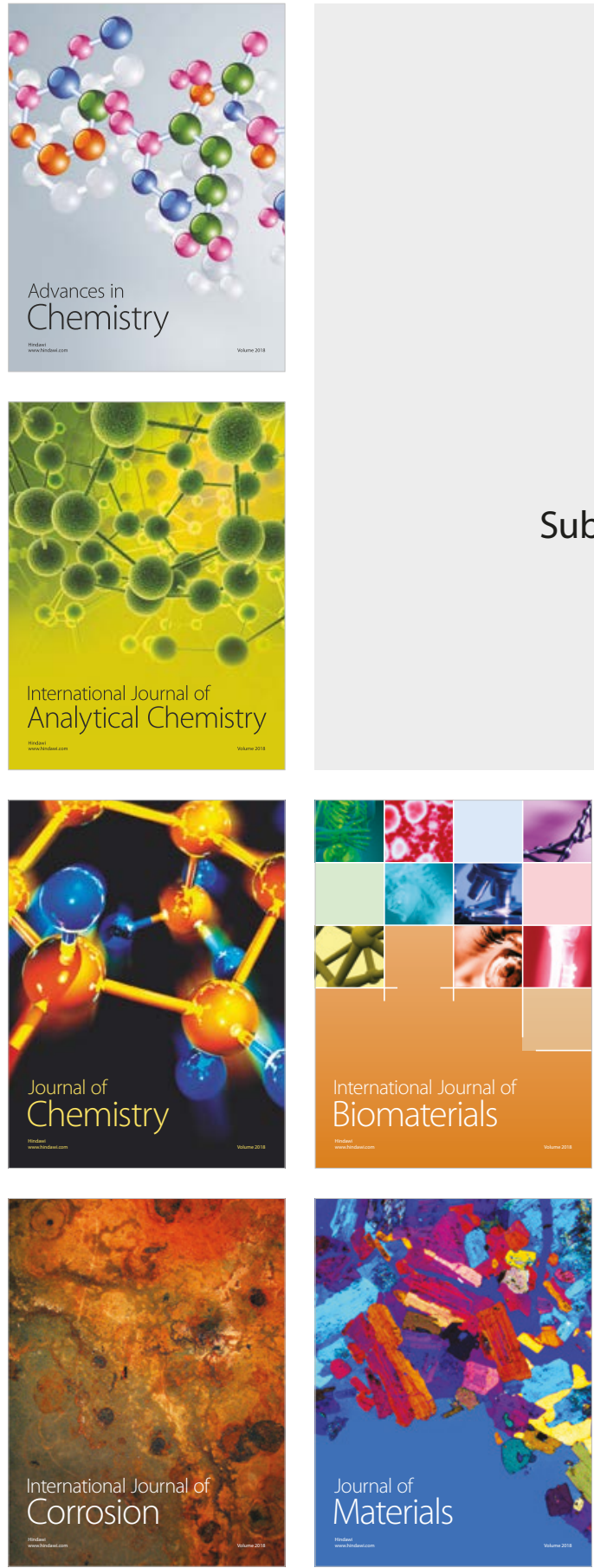

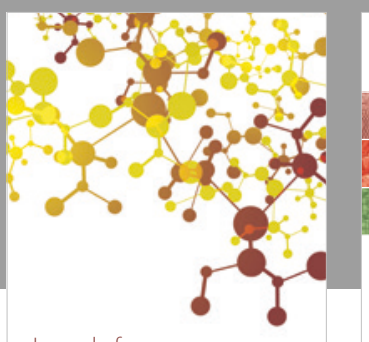

Journal of

Applied Chemistry
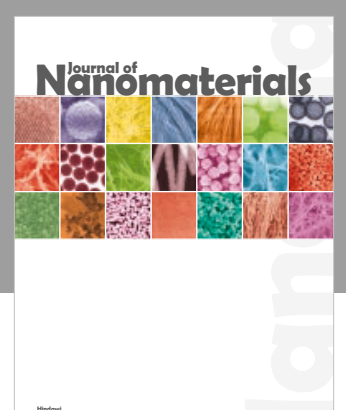

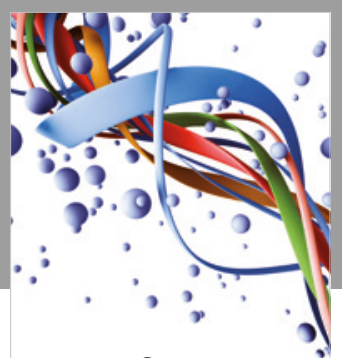

Scientifica

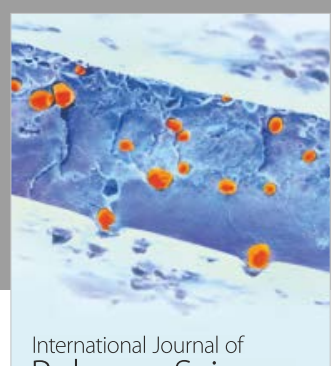

Polymer Science

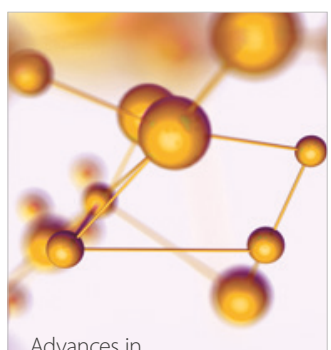

Physical Chemistry
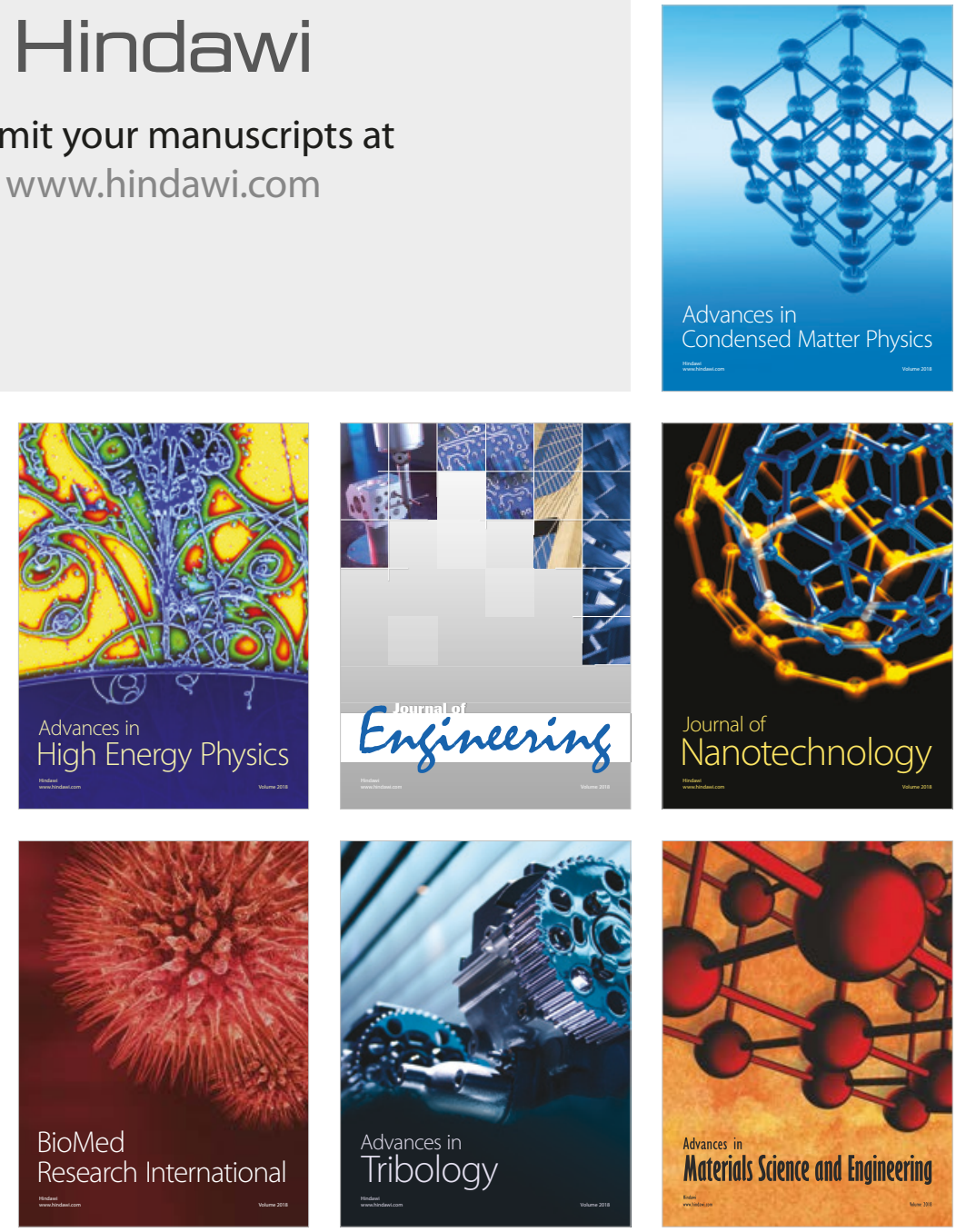